Article

\title{
Lymphocystis Disease Virus (Iridoviridae) Enters Flounder (Paralichthys olivaceus) Gill Cells via a Caveolae-Mediated Endocytosis Mechanism Facilitated by Viral Receptors
}

\author{
Xiuzhen Sheng ${ }^{1}$, Ying Zhong ${ }^{1}$, Jing Zeng ${ }^{1}$, Xiaoqian Tang ${ }^{1}$, Jing Xing ${ }^{1}$, Heng Chi ${ }^{1}$ and \\ Wenbin Zhan ${ }^{1,2, *}$ \\ 1 Laboratory of Pathology and Immunology of Aquatic Animals, KLMME, Ocean University of China, \\ Qingdao 266003, China; xzsheng@ouc.edu.cn (X.S.); yzhong@shou.edu.cn (Y.Z.); cj7011@stu.ouc.edu.cn (J.Z.); \\ tangxq@ouc.edu.cn (X.T.); xingjing@ouc.edu.cn (J.X.); chiheng@ouc.edu.cn (H.C.) \\ 2 Function Laboratory for Marine Fisheries Science and Food Production Processes, \\ Qingdao National Laboratory for Marine Science and Technology, Qingdao 266071, China \\ * Correspondence: wbzhan@ouc.edu.cn
}

Received: 3 June 2020; Accepted: 29 June 2020; Published: 2 July 2020

check for updates

\begin{abstract}
In previous research, voltage-dependent anion channel protein 2 (VDAC2) and the receptor of activated protein C kinase 1 (RACK1) in flounder (Paralichthys olivaceus) were confirmed as functional receptors for lymphocystis disease virus (LCDV) entry; however, the underlying mechanism of VDAC2- and RACK1-mediated LCDV entry remains unclear. In this study, we elucidated the endocytosis pathway of LCDV entry into flounder gill (FG) cells by treatment with specific inhibitory agents, siRNAs, and co-localization analysis. LCDV entry was significantly inhibited by the disruption of caveolae-mediated endocytosis, dynamin, and microtubules, and the knockdown of caveoline-1 and dynamin expression, but was not inhibited by the disruption of clathrin-mediated endocytosis, micropinocytosis, or low-pH conditions. The disruption of caveolae-mediated and clathrin-mediated endocytosis was verified by the internalization of cholera toxin subunit B (CTB) and transferrin, respectively. Confocal immunofluorescence assay demonstrated that LCDV was co-localized with VDAC2 and RACK1, CTB was co-localized with VDAC2 and RACK1 and partially with LCDV, but transferrin was not co-localized with LCDV, VDAC2, or RACK1, indicating that LCDV utilized the same pathway as CTB, i.e., caveolae-mediated endocytosis. This was different from the pathway of transferrin, which used clathrin-mediated endocytosis. Furthermore, caveolin-1 was co-localized with LCDV, VDAC2, and RACK1, suggesting that caveolin-1 was involved in LCDV entry. These results revealed for the first time that LCDV entered into FG cells via caveolae-mediated endocytosis facilitated by VDAC2 and RACK1 receptors, relying on dynamin and microtubules in a $\mathrm{pH}$-independent manner, which provided new insight into the molecular mechanisms of LCDV entry and potential for the development of antiviral agents, expanding our understanding of iridovirus infection.
\end{abstract}

Keywords: flounder gill cells; viral receptor; voltage-dependent anion channel protein 2; receptor of activated protein $\mathrm{C}$ kinase 1

\section{Introduction}

Lymphocystis disease virus (LCDV), an enveloped DNA virus belonging to the genus Lymphocystivirus within the family Iridoviridae [1,2], is the causative agent of lymphocystis disease, which infects more than 140 wild and cultured species of marine, brackish, and freshwater fish worldwide [3,4]. Although the disease rarely causes death, it may lead to secondary infection by 
other microorganisms, resulting in high mortalities [5,6]. The antigenicity, biological and epidemic characteristics, and prevention and treatment of LCDV have been extensively studied [7-10]. We have identified 27.8 kDa protein as a cellular receptor for LCDV from flounder (Paralichthys olivaceus) gill (FG) cells [11], a cell line derived from the gill tissue of a flounder [12]. Moreover, a $32 \mathrm{kDa}$ envelope protein of LCDV was found to function as a viral attachment protein (VAP), and the interaction of the $32 \mathrm{kDa}$ VAP with the $27.8 \mathrm{kDa}$ putative receptor protein initiates LCDV infection in FG cells [13]; monoclonal antibodies (MAbs) against the $32 \mathrm{kDa}$ VAP can effectively neutralize LCDV infection [14]. Recently, voltage-dependent anion channel protein 2 (VDAC2) and the receptor of activated protein C kinase 1 (RACK1) have been identified among the putative $27.8 \mathrm{kDa}$ receptor protein as the functional receptor for LCDV entry [15]. However, the LCDV infection mechanism remains to be elucidated.

Voltage-dependent anion channel protein (VDAC) is abundant in caveolae [16-18], along with other proteins and lipids, such as caveolin- 1 and cholesterol. In addition, caveolae also contain a large number of signaling molecules, such as $G$ protein, $G$ protein-coupled receptors, and tyrosine kinase receptors, and downstream signaling molecules, e.g., protein kinase A (PKA) and protein kinase C (PKC) [19]. RACK1 functions as a scaffold protein involved in regulation of PKA and PKC proteins [19,20], while PKC is an important regulator of caveolae-mediated endocytosis [21]. Cell membrane VDAC has also been reported to act as a scaffold protein [18]. Although VDAC2 and RACK1 are functional receptors for LCDV, infection by LCDV can be blocked by pre-incubation with anti-VDAC2 and anti-RACK1 antibodies or knockdown of VDAC2 and RACK1 expression through short interfering RNAs (siRNAs), and VDAC2/RACK1 expression on LCDV-nonpermissive epithelial papillosum cell (EPC) conferred susceptibility to LCDV infection [15]. Nonetheless, the underlying mechanism of VDAC2- and RACK1-mediated LCDV entry remains unclear, and further studies focusing on the entry pathway of LCDV facilitated by VDAC2 and RACK1 receptors are required.

Virus-entry pathways are largely defined by interactions between virus particles and their receptors at the cell surface [22]; elucidating this complex interaction is necessary for a full understanding of how viruses invade their hosts [23]. There are two primary routes by which enveloped viruses enter host cells: membrane fusion and endocytosis. The main viral endocytosis pathways are clathrin-mediated endocytosis, caveolae-mediated endocytosis, macropinocytosis, and phagocytosis [21]. The type of endocytosis is not only dependent on the characteristics of the virion itself but is also related to host cytokines, signaling pathways, and receptor proteins [24]. The most commonly used endocytosis pathway is clathrin-mediated endocytosis, which is a continuous process characterized by rapidity and efficiency involving the formation, assembly, and budding of clathrin-coated pits (CCPs) [25]. During the formation of CCPs, clathrin interacts with a series of signaling molecules, including Eps15, adaptor protein AP12, and dynamin GTPase [26,27]. CCPs are then transferred to acidic endosomes, lysosomes, and Golgi apparatus [25]. Endocytic vesicles provide an acidic environment that can help virus uncoating and genome release; therefore, clathrin-mediated endocytosis is sensitive to $\mathrm{pH}$ change $[28,29]$. Another commonly used entry pathway is caveolae-mediated endocytosis, which is a slower process than clathrin-mediated endocytosis. In caveolae-mediated endocytosis, viruses first bind to regions of sphingolipids and cholesterol on the cell membrane known as caveolae, developed from lipid rafts [30-32], so this pathway is generally dependent on membrane cholesterol [19]. Caveolae are flask-shaped invaginations of the plasma membrane that are widely distributed and play important roles in signal transduction $[19,33]$. Caveolin-1 is a marker protein of caveolae formation and also a scaffold protein and regulator of many signaling molecules [34]. Dynamin participates in the formation and scission of CCPs or caveolae, playing important roles in both caveolae-mediated and clathrin-mediated endocytosis [29]. Microtubules serve as tracks for vesicles moving along the membrane system $[35,36]$. Macropinocytosis is associated with plasma membrane ruffling induced by the activation of actin or microfilaments connected to the plasma membrane [37]. Through this pathway, the virus first activates signaling molecules such as Rac GTPases, $\mathrm{Na}^{+} / \mathrm{H}^{+}$exchangers, $\mathrm{PKC}$, and phosphoino-sitide 3-kinase (PI3K) [37], which trigger actin remodeling, resulting in membrane folds and bubbles extending from the cell surface. These membrane ruffles fold or fall down on their 
own to surround the extracellular virus, allowing virus particles to internalize and penetrate into the cytoplasm [38]. Additionally, viruses can use other endocytosis mechanisms to enter host cells, but there have been limited studies on the molecular mechanisms and receptors involved [21,39,40]. Cholera toxin subunit B (CTB) and transferrin are often used as indicators of caveolae- and clathrin-mediated endocytosis, respectively, because CTB is known to enter cells via caveolae-mediated endocytosis, whereas transferrin enters through clathrin-mediated endocytosis [41,42].

Members of the family Iridoviridae (iridoviruses) can infect invertebrates and poikilothermic vertebrates, such as insects, fish, amphibians, and reptiles [43,44]. Viruses in the genera, Lymphocystivirus, Megalocytivirus, and Ranavirus, are capable of infecting teleost fish. Infectious spleen and kidney necrosis virus (ISKNV) of the genus Megalocytivirus enters host cells via caveolae-dependent endocytosis [35], whereas the Singapore grouper iridovirus (SGIV) of the genus Ranavirus enters host cells via clathrin-mediated endocytosis and macropinocytosis pathways in a $\mathrm{pH}$-dependent manner [45]. In the present study, we explored the entry pathway of LCDV into FG cells through interaction with VDAC2 and RACK1 receptor proteins by treating cells with specific inhibitory agents, siRNA, and co-localization analysis. We found that caveolae-mediated endocytosis was involved in LCDV entry. These results not only contribute to elucidating the cellular entry mechanisms of LCDV in fish but also expand our understanding of iridovirus infection.

\section{Results}

\subsection{Specificity of Mouse Anti-Clathrin, Anti-Caveolin, and Anti-Dynamin Polyclonal Antibodies}

Keyhole limpet hemocyanin (KLH)-conjugated polypeptides of clathrin, caveolin, and dynamin were used to immunize mice, and mouse anti-clathrin, anti-caveolin, and anti-dynamin polyclonal antibodies were produced. The enzyme-linked immunosorbent assay (ELISA) results indicate that the optical density (OD) values of mouse anti-clathrin, anti-caveolin, and anti-dynamin polyclonal antibodies are greatly higher than those of mouse pre-immune serum negative controls; the titer of mouse anti-dynamin polyclonal antibody was slightly lower than those of anti-clathrin and anti-caveolin Figure 1A. Fluorescence-activated cell sorting (FACS) indicated $88.7 \%, 81.4 \%$, and $81.1 \%$ clathrin-, caveolin-, and dynamin-positive cells, respectively Figure S1. Indirect immunofluorescence assay (IFA) showed positive red signals in FG cells, but no positive signals in negative controls, suggesting the mouse anti-clathrin, anti-caveolin, and anti-dynamin polyclonal antibodies could recognize the corresponding proteins on FG cells Figure 1B. All these results indicate that the mouse anti-clathrin, anti-caveolin, and anti-dynamin polyclonal antibodies had good specificity and could be used for the following experiments.

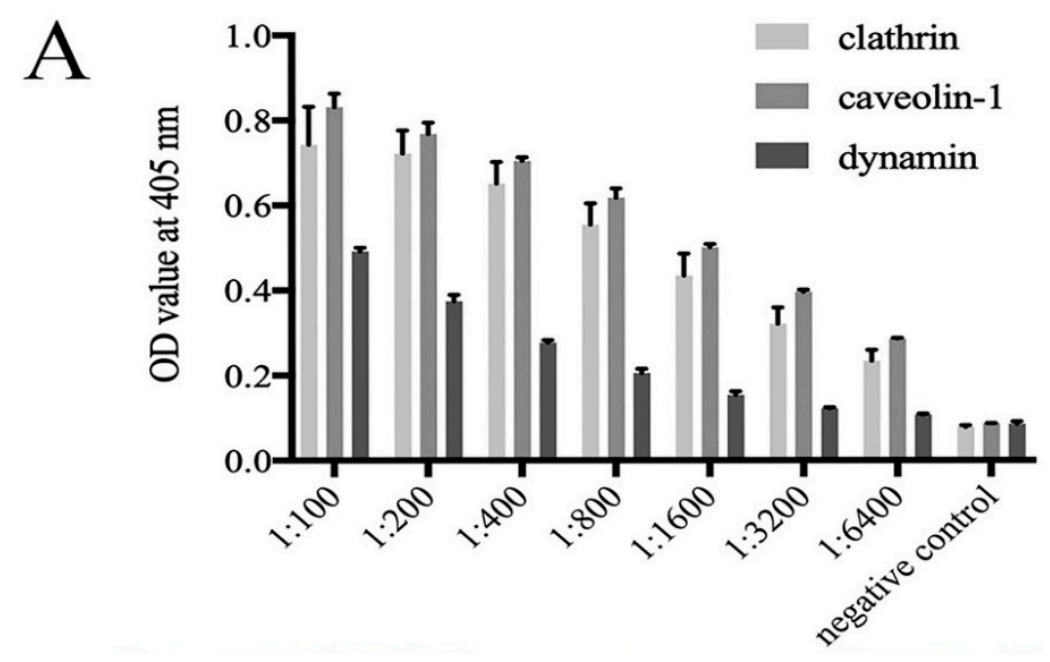

Figure 1. Cont. 


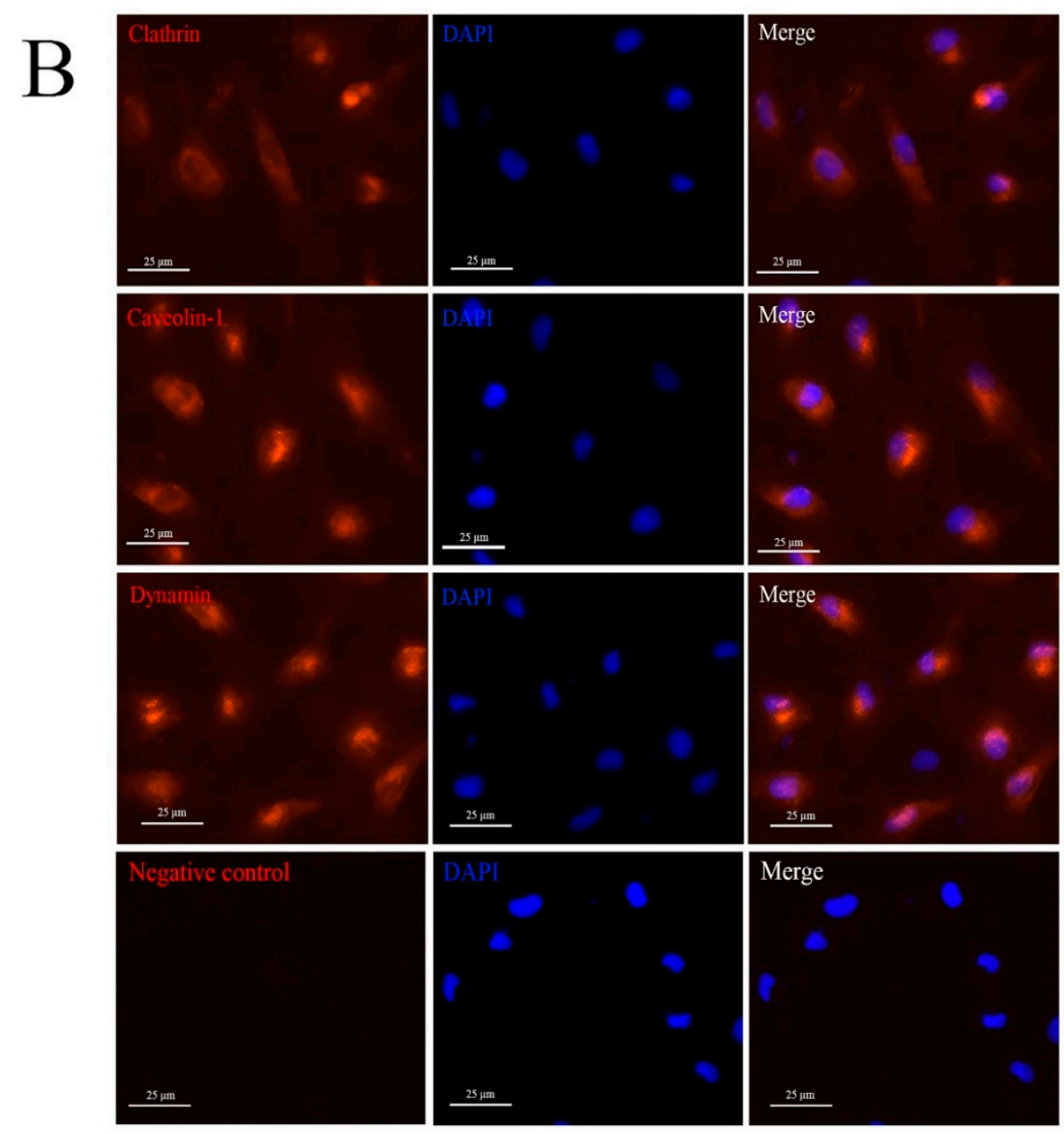

Figure 1. Specificity analysis of mouse anti-clathrin, anti-caveolin-1, and anti-dynamin polyclonal antibodies. (A) The titer of mouse anti-clathrin, anti-caveolin-1, and anti-dynamin polyclonal antibodies analyzed by ELISA; error bars represent standard deviations (SD, $n=3)$. (B) The indirect immunofluorescence assay (IFA) of mouse anti-clathrin, anti-caveolin-1, and anti-dynamin polyclonal antibodies with FG cells; bars $=25 \mu \mathrm{m}$. Mouse pre-immune serum was used as a negative control.

\subsection{LCDV Entry Requires Membrane Cholesterol}

To elucidate whether LCDV entry into FG cells depends on cellular cholesterol, we treated cells with different concentrations of Methyl- $\beta$-cyclodextrin $(\mathrm{M} \beta C D)$ to eliminate cholesterol from cell membranes and destroy caveolae-mediated endocytosis both prior to and post LCDV infection. When FG cells were pre-incubated with $\mathrm{M} \beta C D$ for $1 \mathrm{~h}$ and then infected with LCDV, the percentage of LCDV-positive cells and virus copy numbers were significantly decreased $(p<0.05)$ (Figure 2A, Figure S2A), but cell viability was not obviously affected by $M \beta C D$ treatment (Figure $2 A$ ). However, when FG cells were treated with M $\beta C D$ post LCDV entry, the percentage of LCDV-positive cells or virus copy numbers were not obviously decreased regardless of the concentration of $M \beta C D$ (Figure $2 B$, Figure S2B). These results indicate that cellular cholesterol was needed for LCDV entry into FG cells, but after virus entry, LCDV replication was not affected by cellular cholesterol. 
A

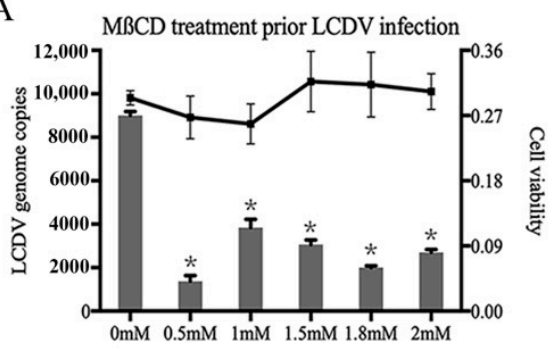

C
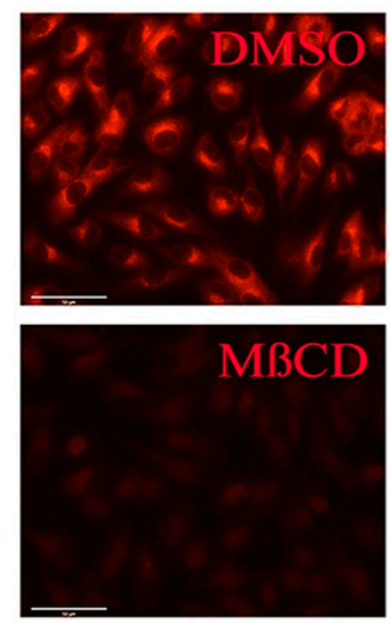
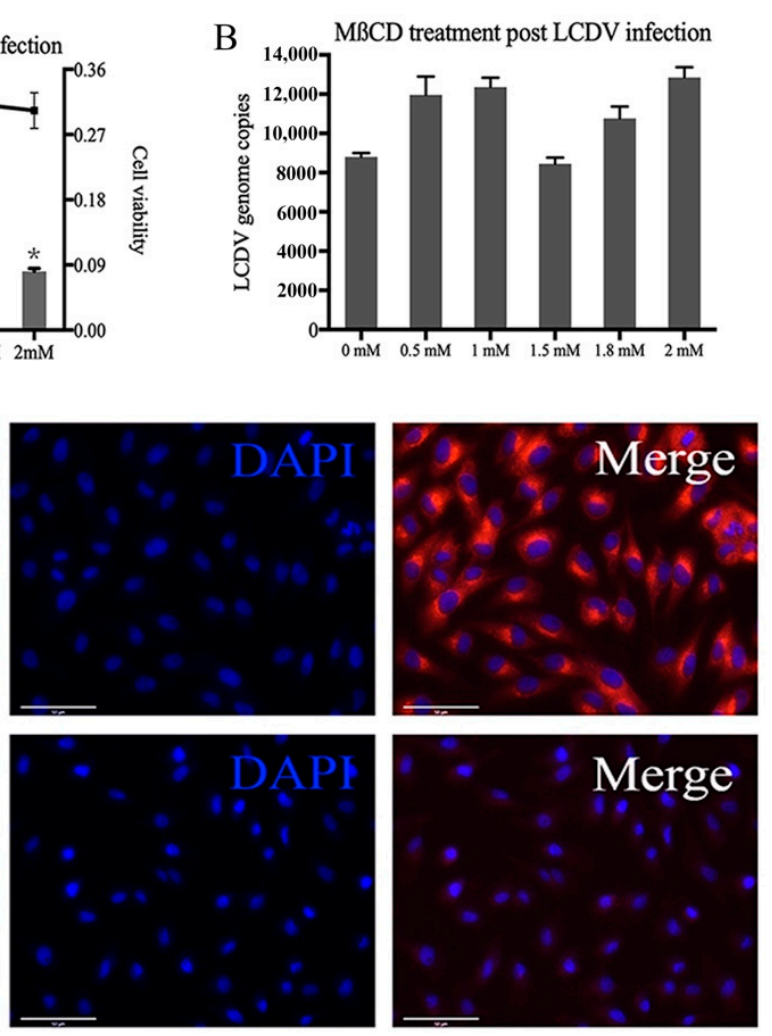

Figure 2. Cholesterol is required for LCDV entry. (A) FG cells were pre-incubated with $\mathrm{M} \beta C D$ at $22{ }^{\circ} \mathrm{C}$ for $1 \mathrm{~h}$, then incubated with LCDV for another $1 \mathrm{~h}$ in the continued presence of reagent. LCDV copy numbers in FG cells were detected by qPCR; the histogram represents virus copy numbers and the line graph represents cell viability. (B) FG cells were infected with LCDV for $1 \mathrm{~h}$ and then treated with different concentrations of $\mathrm{M} \beta C D$ at $22^{\circ} \mathrm{C}$ for $1 \mathrm{~h}$. LCDV copy numbers were detected by qPCR. (C) FG cells were treated with $1.5 \mathrm{mM} \mathrm{M} \beta \mathrm{CD}$ and then incubated with Alexa fluor 647 conjugated CTB. the fluorescence intensity of CTB in FG cells was observed using fluorescence microscopy; bars $=50 \mu \mathrm{m}$. FG cells treated with DMSO instead of M $\beta C D$ prior to and post LCDV infection served as negative controls. Error bars (A,B) represent standard deviations (SD, $n=3)$. Asterisks denote significant differences compared with negative controls ( $p<0.05$, one-way ANOVA).

To verify the disruption of cellular cholesterol, we analyzed the internalization of CTB. The percentage of CTB-positive FG cells was greatly reduced (Figure S2C) and the fluorescence intensity was obviously weakened compared with those of the negative control (Figure 2C), suggesting that cellular cholesterol was eliminated by $\mathrm{M} \beta \mathrm{CD}$.

\subsection{LCDV Entry into FG Cells Depends on Dynamin and Microtubules}

To investigate whether LCDV entry into FG cells is dependent on dynamin and microtubules, we pretreated FG cells with different concentrations of dynasore or nocodazole before LCDV inoculation. FACS showed that, in the presence of greater than $10 \mu \mathrm{M}$ dynasore or $5 \mu \mathrm{M}$ nocodazole, the percentage of LCDV-positive cells was decreased as compared with that in negative controls (Figure 3A, Figure S3A); meanwhile, LCDV copy numbers in FG cells were significantly reduced $(p<0.05)$ (Figure 3B, Figure S3B), indicating that dynamin and microtubules were required for LCDV entry. The MTT assay results show that cell viability was not obviously affected by dynasore or nocodazole treatment (Figure 3A,B). 

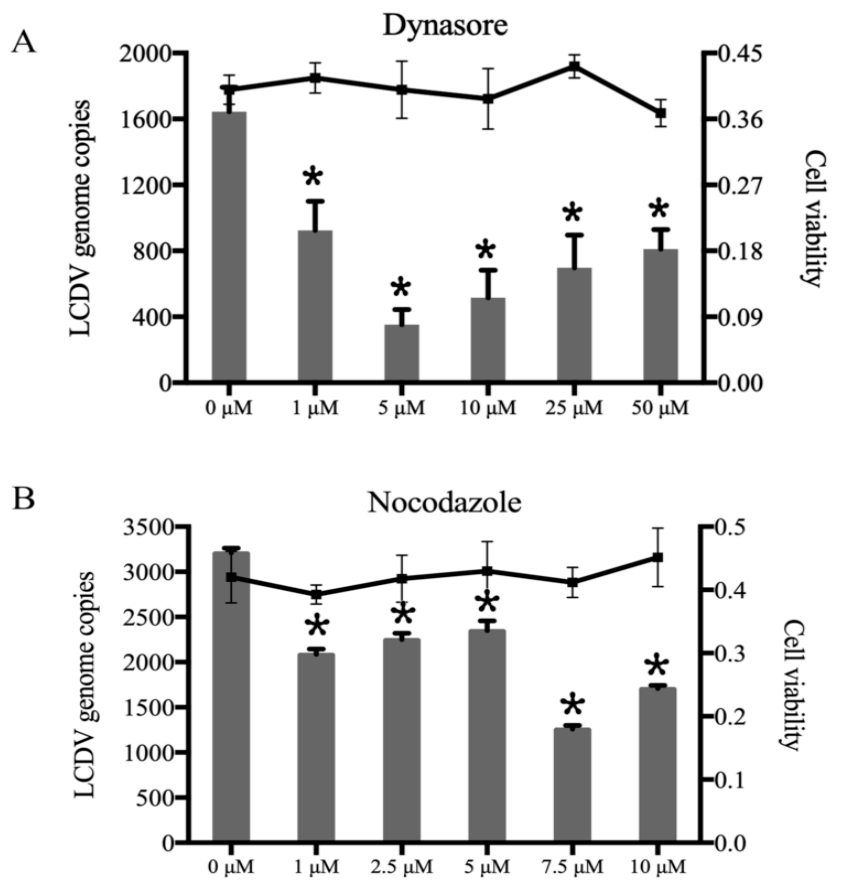

Figure 3. LCDV entry depends on dynamin and microtubules. (A) FG cells were pre-incubated with dynasore, and then infected with LCDV. LCDV copy numbers were detected by qPCR; the histogram represents virus copy numbers and the line graph represents cell viability. (B) FG cells were pre-incubated with nocodazole and then infected with LCDV. LCDV copy numbers were detected by qPCR; the histogram represents virus copy numbers and the line graph represents cell viability. FG cells pre-incubated with DMSO instead of dynasore or nocodazole served as negative controls. Error bars $(\mathbf{A}, \mathbf{B})$ represent $\mathrm{SD}(n=3)$. Asterisks denote significant differences compared with negative controls $(p<0.05$, one-way ANOVA).

\subsection{LCDV Entry Is Caveolae-Dependent}

To disrupt caveolae-mediated endocytosis, we pre-incubated FG cells with different concentrations of the cholesterol-binding reagents nystatin and filipin III, the tyrosine kinase inhibitor genistein, and the PKC activation inhibitor phorbol 12-myristate 13-acetate (PMA) before LCDV infection. The FACS results indicate that the percentage of LCDV-positive cells decreased significantly as compared with negative controls and in the presence of $2.5 \mu \mathrm{M}$ genistein, $100 \mu \mathrm{g} / \mathrm{mL}$ nystatin, $10 \mu \mathrm{g} / \mathrm{mL}$ filipin III, and $1 \mu \mathrm{M}$ PMA (Figure S4A-D). The quantitative PCR (qPCR) results demonstrate that LCDV copy numbers were also significantly reduced $(p<0.05)$ (Figure $4 \mathrm{~A}-\mathrm{D})$. Moreover, we detected the internalization of CTB into FG cells, and the amounts of CTB-positive cells (Figure S4E) and their fluorescence intensity (Figure $4 \mathrm{E}$ ) were obviously decreased compared with negative controls, indicating that caveolae-mediated endocytosis was disrupted. The MTT assay results reveal that cell viability was not obviously affected by treatment with cholesterol-binding reagents (Figure 4A-D). 

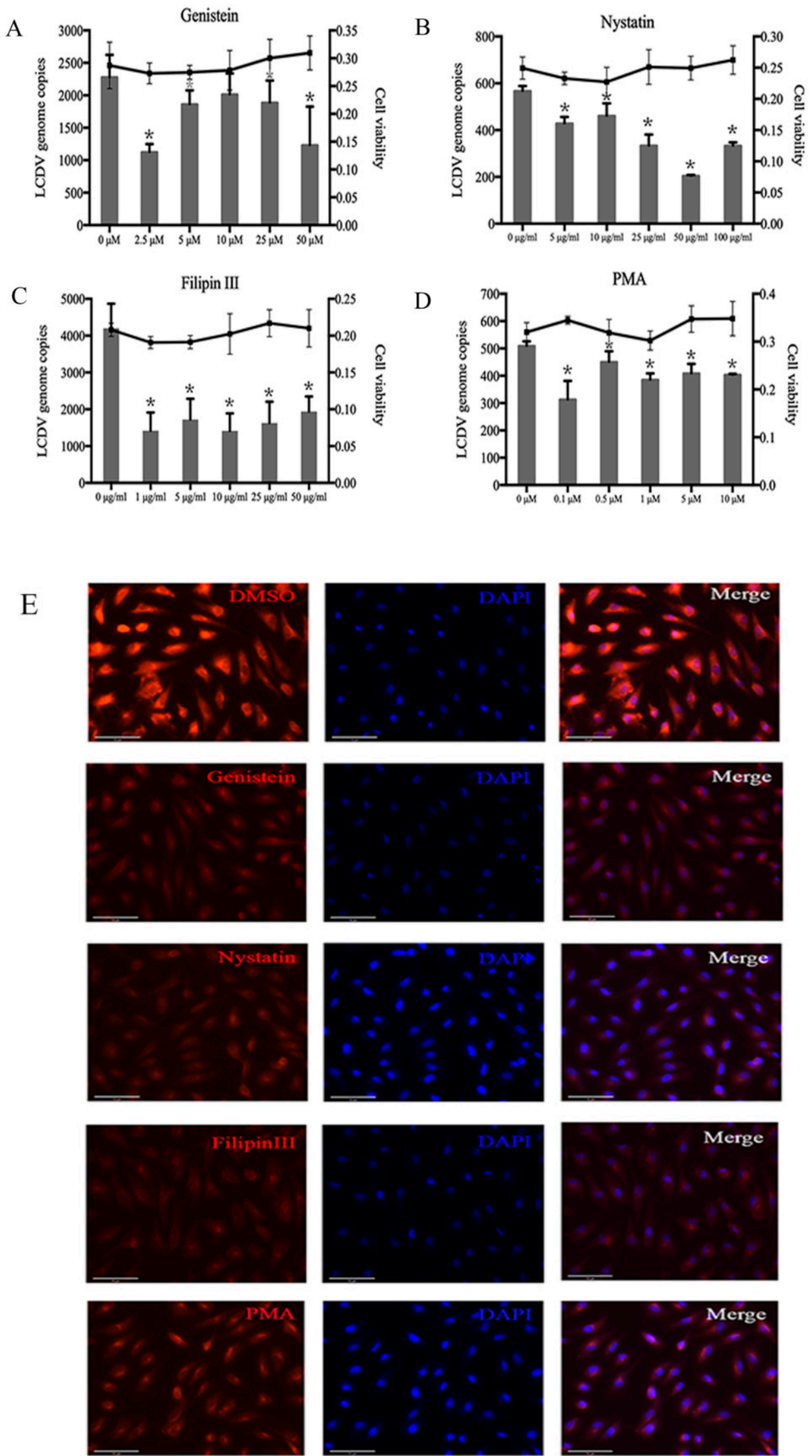

Figure 4. LCDV enters cells via caveola-dependent endocytosis. FG cells were pre-incubated with genistein (A), nystatin (B), filipin III (C), or PMA (D), and then infected with LCDV. LCDV copy numbers 
in FG cells were detected by qPCR; the histogram represents virus copy numbers and the line graph represents cell viability. (E) FG cells were treated with $10 \mu \mathrm{M}$ genistein, $25 \mu \mathrm{g} / \mathrm{mL}$ nystatin, $10 \mu \mathrm{g} / \mathrm{mL}$ filipin III, or $1 \mu \mathrm{M}$ PMA, then incubated with Alexa fluor 647 conjugated CTB. The fluorescence intensity of CTB in FG cells was observed using fluorescence microscopy; bars $=50 \mu \mathrm{m}$. FG cells treated with DMSO instead of genistein, nystatin, filipin III, or PMA served as negative controls. Error bars $(\mathrm{A}-\mathrm{D})$ represent $\mathrm{SD}(n=3)$. Asterisks indicate significant differences compared with negative controls $(p<0.05$, one-way ANOVA).

\subsection{LCDV Entry Is $p H$ - and Clathrin-Independent}

To verify whether LCDV entry is dependent on cellular $\mathrm{pH}$ and clathrin, we disrupted clathrin-mediated endocytosis using sucrose and chlorpromazine (CPZ), and cellular low-pH conditions using chloroquine (CQ) and $\mathrm{NH}_{4} \mathrm{Cl}$. FG cells were pre-incubated with different concentrations of inhibitory agents before LCDV infection, and the blocking of LCDV entry was detected by FACS and qPCR. No significant changes in the percentages of LCDV-positive cells (Figure S5A,B) or virus copy numbers (Figure $5 \mathrm{~A}, \mathrm{~B}$ ) were observed in the presence of different concentrations of $\mathrm{CQ}$ or $\mathrm{NH}_{4} \mathrm{Cl}$, indicating that LCDV entry did not correlate with the $\mathrm{pH}$ change of endocytic vesicles. Similarly, there were no obvious changes in the percentage of LCDV-positive cells (Figure S5C,D) or virus copy numbers (Figure 5C,D) when FG cells were pre-incubated with different concentrations of sucrose or $\mathrm{CPZ}$, suggesting that clathrin-mediated endocytosis was not involved in LCDV entry.

To verify that the above reagents disrupted clathrin-mediated endocytosis, we the detected internalization of transferrin in FG cells using FACS and IFA, and revealed the decreased amounts of transferrin-positive cells (Figure S5E) and fluorescence intensity (Figure 5E) compared with negative controls. The MTT assay demonstrated that sucrose, $\mathrm{CPZ}, \mathrm{CQ}$, or $\mathrm{NH}_{4} \mathrm{Cl}$ treatment had no obvious influence on FG cell viability (Figure 5A-D). These results demonstrate that LCDV entry into FG cells was independent of $\mathrm{pH}$ and clathrin-mediated endocytosis.

A

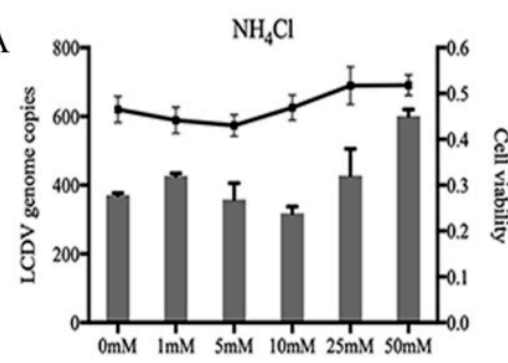

C

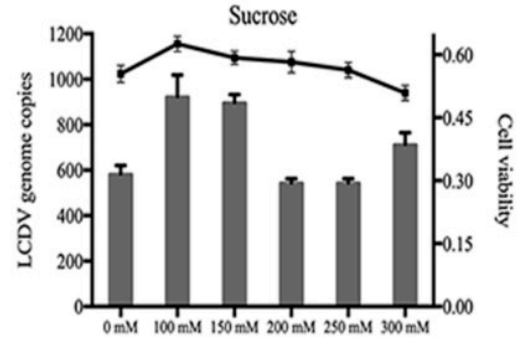

$\mathrm{CQ}$

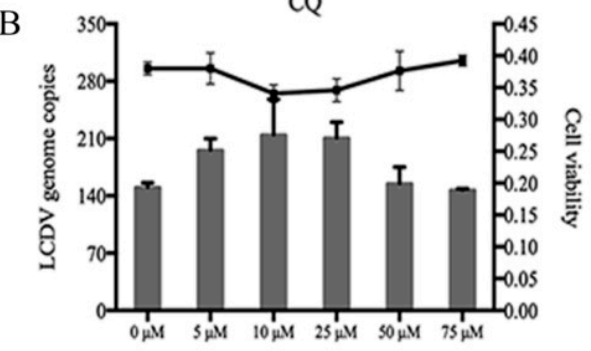

$\mathrm{CPZ}$

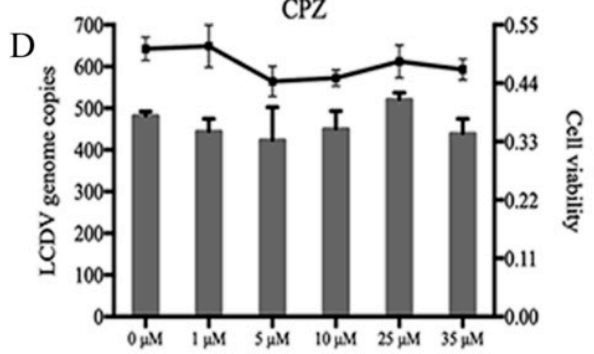

Figure 5. Cont. 
$\mathrm{E}$
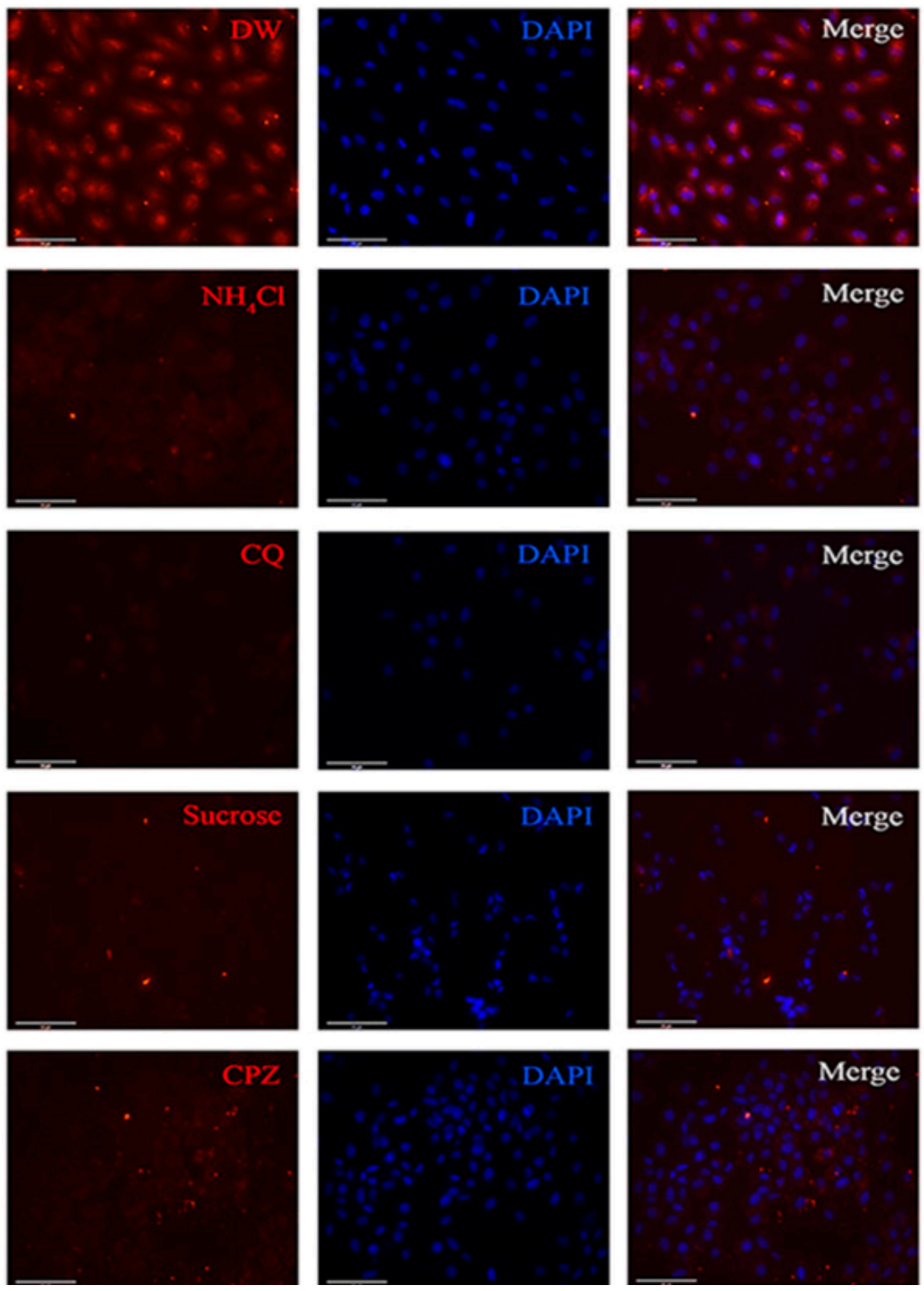

Figure 5. LCDV entry is $\mathrm{pH}$ - and clathrin-independent. FG cells were pre-incubated with $\mathrm{NH}_{4} \mathrm{Cl}$ (A), CQ (B), sucrose (C), or CPZ (D), and then infected with LCDV. LCDV copy numbers were detected by qPCR; the histogram represents virus copy numbers and the line graph represents cell viability. (E) FG cells were treated with $10 \mathrm{mM} \mathrm{NH}_{4} \mathrm{Cl}, 25 \mu \mathrm{M}$ CQ, $200 \mathrm{mM}$ sucrose, or $10 \mu \mathrm{M} \mathrm{CPZ}$, then incubated with Alexa fluor 647 conjugated transferrin. The fluorescence intensity of transferrin in FG cells was observed using fluorescence microscopy; bars $=50 \mu \mathrm{m}$. FG cells treated with distilled water instead of $\mathrm{NH}_{4} \mathrm{Cl}, \mathrm{CQ}$, sucrose or $\mathrm{CPZ}$ served as negative controls. Error bars represent $\mathrm{SD}(n=3)$.

\subsection{LCDV Entry Is Macropinocytosis-Independent}

To elucidate whether LCDV entry into FG cells is dependent on macropinocytosis, FG cells were pretreated with different concentrations of wortmannin to inhibit PI3K and 5-( $N$-ethyl- $N$-isopropyl) amiloride (EIPA) to block $\mathrm{Na}^{+} / \mathrm{H}^{+}$exchange before LCDV infection; the inhibition of LCDV entry was determined by FACS and qPCR. No obvious changes in the percentage of LCDV-positive cells (Figure S6A,B) or virus copy numbers were observed regardless of wortmannin or EIPA concentration (Figure 6A,B). Cell viability was not affected by reagent treatment as compared with negative controls (Figure 6A,B). These results indicate that LCDV entry was independent of macropinocytosis. 

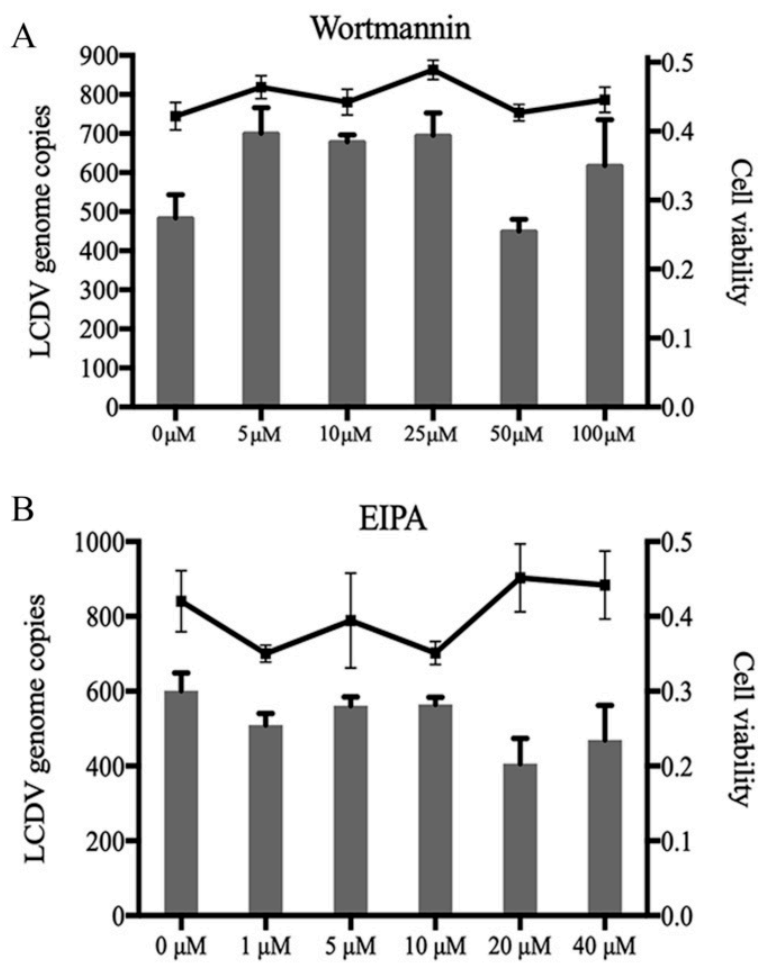

Figure 6. LCDV entry is micropinocytosis independent. FG cells were pre-incubated with wortmannin (A) or EIPA (B), LCDV copy numbers in FG cells were detected by qPCR; the histogram represents virus copy numbers and the line graph represents cell viability. FG cells treated with DMSO instead of wortmannin or EIPA served as negative controls. Error bars represent $\operatorname{SD}(n=3)$.

\subsection{Influence of Clathrin, Caveolin-1, and Dynamin Knockdown in FG Cells on LCDV Infection}

To further elucidate the entry pathway of LCDV into FG cells, siRNAs targeting clathrin, caveolin-1, and dynamin 2 (clathrin-siRNA, caveolin-siRNA, and dynamin-siRNA) were transfected into FG cells, and mRNA levels were monitored by qRT-PCR. In comparison with negative controls transfected with a non-silencing control siRNA (NC-siRNA), clathrin, caveolin, and dynamin gene expression in knockdown FG cells was decreased by 0.57-, 0.78-, and 0.49-fold, respectively $(p<0.05)$ (Figure 7A,D,G). As measured using ImageJ software (a free public domain Java image processing program)(Wayne Rasband, National Institutes of Health, Bethesda, MD, USA), the mean fluorescence intensity of clathrin (16.51 versus 18.2), caveolin (17.49 versus 21.57), and dynamin (18.89 versus 19.06) in FG cells was also obviously weakened as compared with the negative controls, which indicated that expression of clathrin, caveolin and dynamin was down-regulated. Here, the results of one group figure for each specific siRNA was provided as an example (Figure 7B,E,H).

To elucidate the effects of clathrin, caveolin, and dynamin knockdown on LCDV infection, the siRNA-transfected FG cells were further infected with LCDV. The qPCR results reveal that LCDV copy numbers in FG cells transfected with caveolin-siRNA or dynamin-siRNA were significantly reduced $(p<0.05)$ (Figure 7F,I), whereas no obvious changes were observed in FG cells transfected with clathrin-siRNA as compared with negative controls (Figure 7C). This indicated that LCDV entry into FG cells was dependent on caveolae-mediated endocytosis and dynamin, but independent of clathrin-mediated endocytosis. 
A

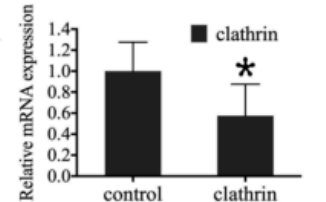

$\mathrm{C}$.
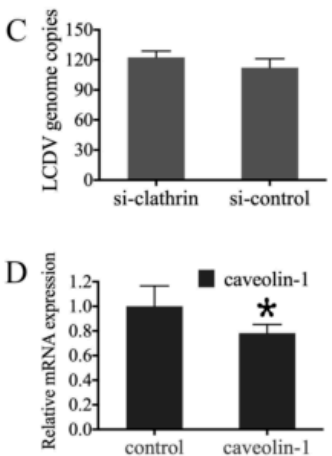

F
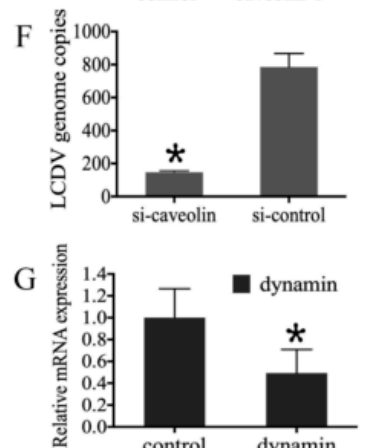

I

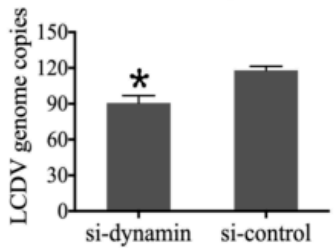

B

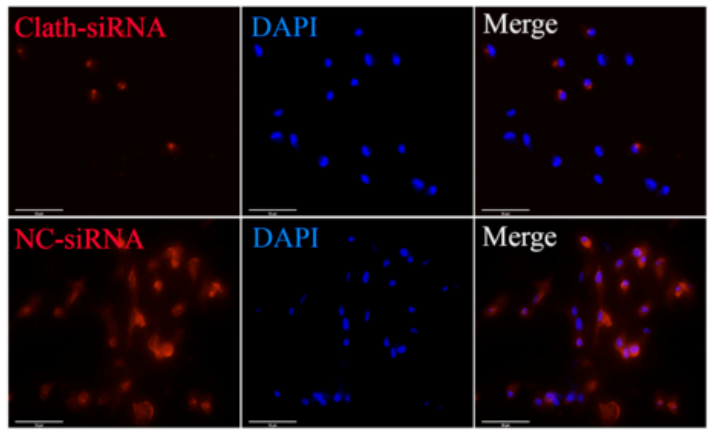

E

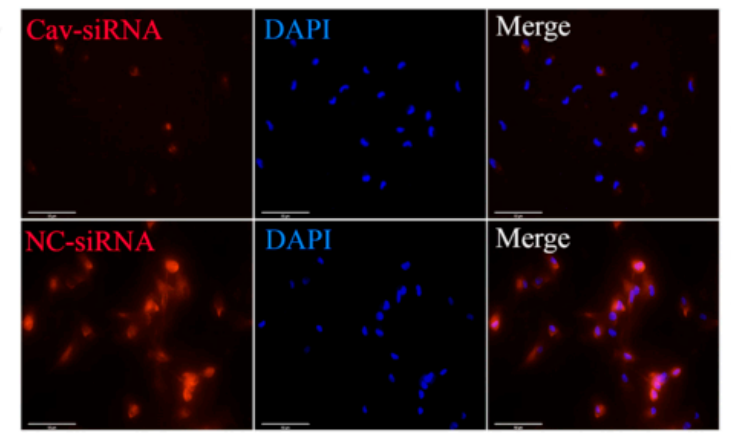

$\mathrm{H}$
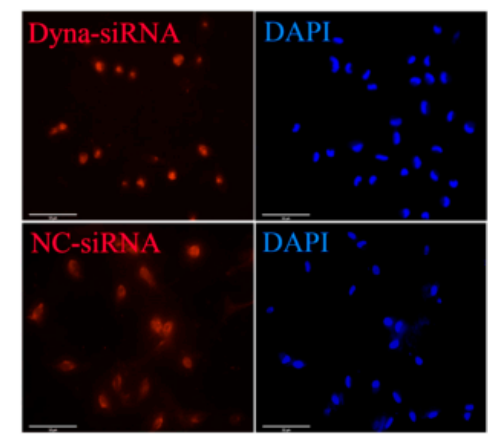
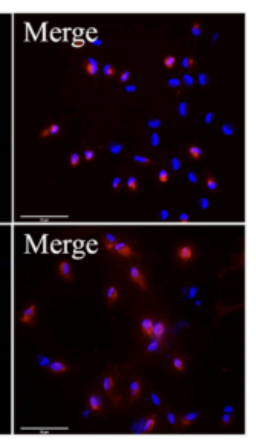
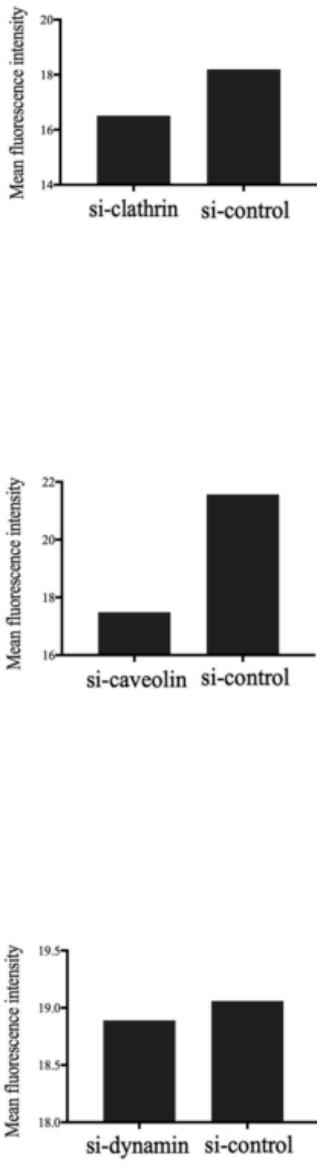

Figure 7. Effect of clathrin, caveolin-1, and dynamin knockdown on the LCDV infection of FG cells. RNA interference sequences were transfected into FG cells and gene expression of clathrin (A), caveolin-1 (D), and dynamin (G) was detected by qPCR; protein expression of clathrin (B), caveolin-1 (E), and dynamin $(\mathbf{H})$ was detected by IFA, bars $=50 \mu \mathrm{m}$, the mean fluorescence intensity of all cells in the field was measured using ImageJ software. RNA interference sequences were transfected into FG cells prior to infection with LCDV, and virus copy numbers in clathrin (C), caveolin-1 (F), and dynamin (I) knockdown FG cells were detected by qPCR. Error bars represent SD $(n=3)$. Asterisks denote significant differences compared with negative controls ( $p<0.05$, one-way ANOVA).

\subsection{Co-Localization of LCDV with RACK1 and VDAC2}

To clarify that LCDV entry into FG cells is mediated by the cellular receptors RACK1 and VDAC2, we determined the co-localization of LCDV with VDAC2 and RACK1 using confocal microscopy. LCDV-positive green signals were present on FG cell membranes and cytoplasm at $2 \mathrm{~h}$ post-infection, accompanied by widely distributed red signals representing VDAC2 and RACK1; merged images of LCDV and RACK1, or LCDV and VDAC2, exhibited many yellow co-localization signals in the cell membrane and cytoplasm (Figure 8A,C). We quantified the merged images using ImageJ software, the co-localization level of merged images was quantified by scattered blots, the diagonal shape of the scattered blots indicated a high level of co-localization, the more the diagonal shape gathers, the higher the degree of co-localization was, while distinct bifurcations indicated no co-localization existing. Scatter plots of LCDV with VDAC2 or LCDV with RACK1 assumed a diagonal shape, indicating a high level of co-localization (Figure 8A). Meanwhile, the values of Pearson's correlation and overlap 
coefficients indicate higher co-localization between LCDV and RACK1 as compared with LCDV and VDAC2 (Pearson's correlation of LCDV and RACK1 versus LCDV and VDAC2: 0.44 versus 0.27; Overlap coefficient of LCDV and RACK1 versus LCDV and VDAC2: 0.93 versus 0.91) (Figure 8B). These results reveal that LCDV was co-localized with the two receptor proteins.

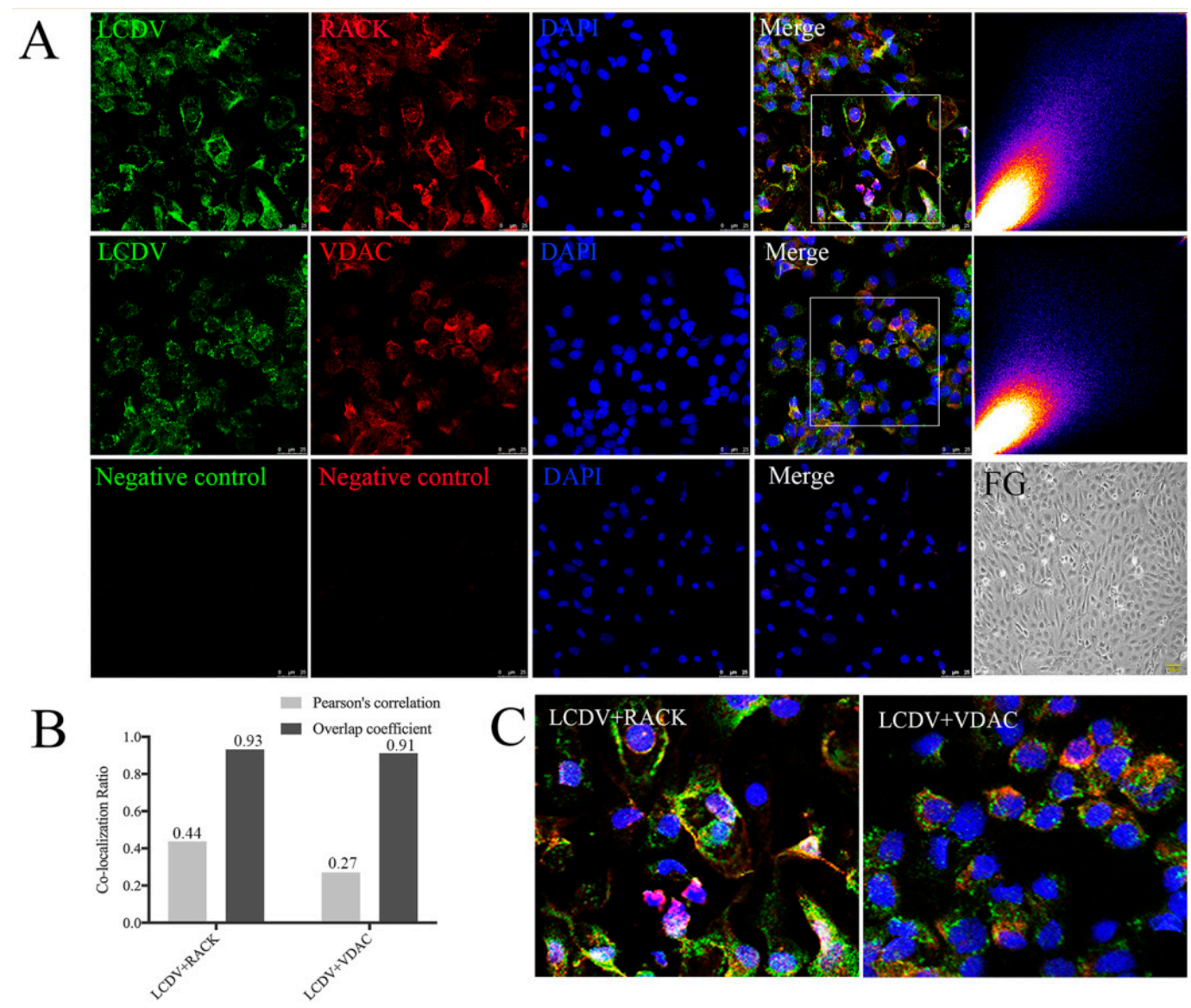

Figure 8. Co-localization of LCDV with VDAC2 and RACK1. (A) The co-localization of LCDV with VDAC2 and RACK1 analyzed by confocal microscopy; scatter plots represent co-localization analysis of the merged images using Image software, the diagonal shape of the scattered blots indicated a high level of co-localization, bars $=25 \mu \mathrm{m}$. Uninfected FG cells were shown as a control, bars $=100 \mu \mathrm{m}$. (B) Pearson's correlation and overlap coefficients of the merged images analyzed by ImageJ software. (C) Higher magnification on framed areas of merged figures in (A). Rabbit pre-immune serum paired with mouse pre-immune serum instead of primary antibodies served as a negative control. The virus inoculation was conducted at $22^{\circ} \mathrm{C}$ for $2 \mathrm{~h}$.

\subsection{Co-Localization of CTB with LCDV, VDAC2, and RACK1}

CTB was used as an indicator of caveolae-mediated endocytosis to determine whether LCDV used the same entry pathway as CTB. The confocal microscopy of CTB with LCDV, VDAC2, or RACK1, separately revealed CTB-positive red signals distributed throughout the cells at $2 \mathrm{~h}$ post-incubation. LCDV-, VDAC2-, and RACK1-positive green signals were also widely distributed at $2 \mathrm{~h}$ post-infection; the merging of CTB images with LCDV, VDAC2, and RACK1 images revealed many yellow co-localization signals in the cell membrane and cytoplasm (Figure 9A,C). The merged images were analyzed using ImageJ software, scatter plots of CTB with VDAC2 or RACK1 presented a diagonal shape, suggesting high co-localization; scatter plots of LCDV with CTB exhibited slight bifurcation, suggesting a lower degree of co-localization than that of CTB with RACK1 and VDAC2 (Figure 9A). The values of Pearson's correlation and overlap coefficients supported co-localization 
between CTB and LCDV (0.19 and 0.9), VDAC2 (0.24 and 0.9), and RACK1 (0.32 and 0.92) (Figure 9B). All of these results indicate that CTB was co-localized with LCDV, VDAC2, and RACK1, and that LCDV might adopt the same entry pathway as CTB.

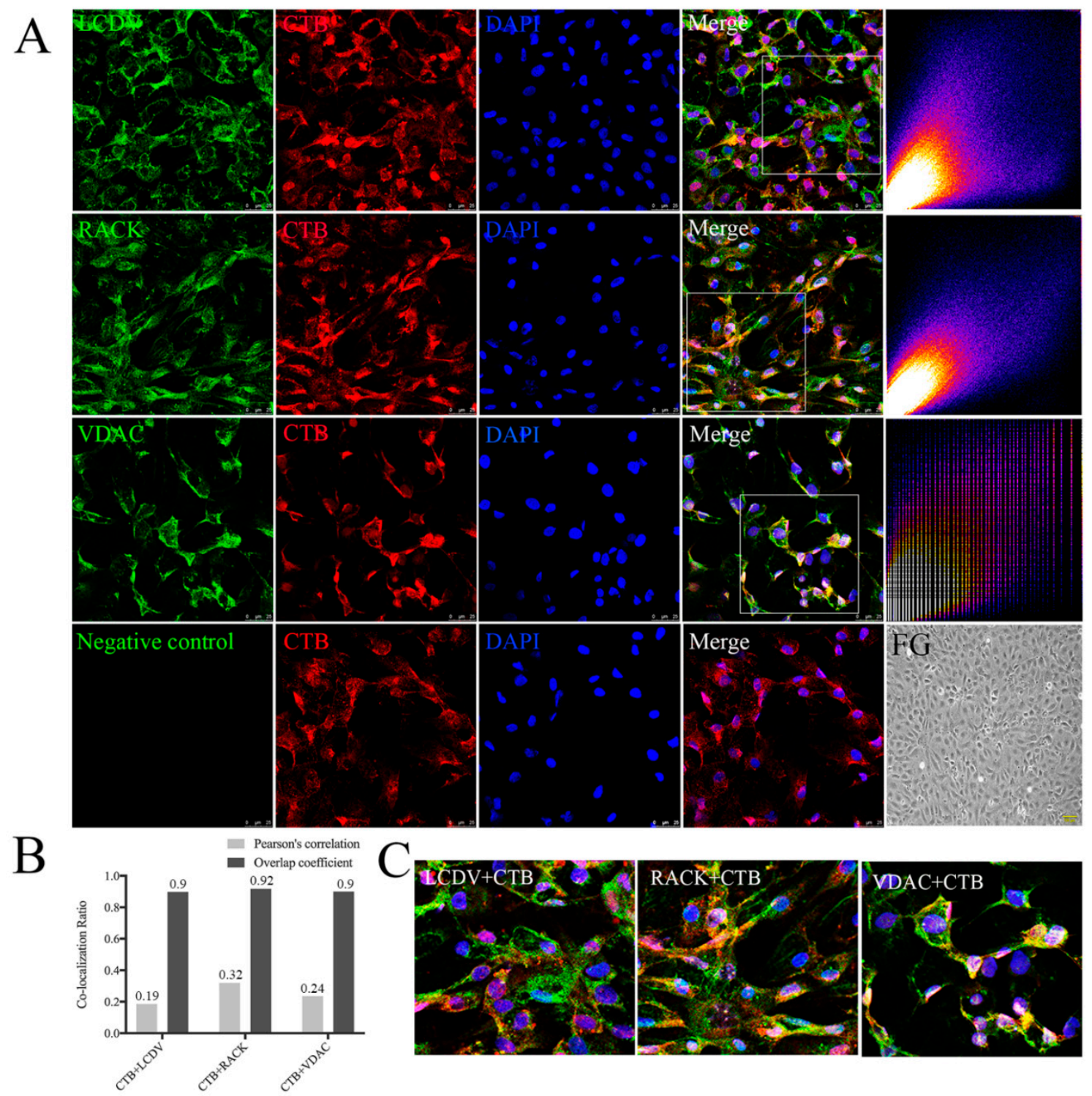

Figure 9. Co-localization of LCDV, VDAC2, and RACK1 with CTB. (A) Co-localization of LCDV, VDAC2, and RACK1 with CTB was analyzed by confocal microscopy; scatter plots represent co-localization analysis of the merged images using ImageJ software, the diagonal shape of the scattered blots indicated a high level of co-localization, bars $=25 \mu \mathrm{m}$. Uninfected FG cells were shown as a control, bars = $100 \mu \mathrm{m}$. (B) Pearson's correlation and overlap coefficients of the merged images analyzed by ImageJ software. (C) Higher magnification on framed areas of merged figures in (A). Rabbit pre-immune serum instead of primary antibody served as a negative control. LCDV and CTB were inoculated to FG cells at $22{ }^{\circ} \mathrm{C}$ for $2 \mathrm{~h}$.

\subsection{LCDV, VDAC2, and RACK1 Are Not Co-Localized with Transferrin}

To examine differences in entry pathways between LCDV and transferrin, we detected the co-localization of transferrin with LCDV, VDAC2, and RACK1, separately, using confocal microscopy. Transferrin-positive red signals appeared in FG cell membranes and cytoplasm at $2 \mathrm{~h}$ post-incubation; LCDV-, VDAC2-, and RACK1-positive green signals were also observed, but no obvious yellow 
co-localization signals were present in the merged images (Figure 10A,C). Merged images of transferrin with LCDV, VDAC2, and RACK1 were analyzed using ImageJ software, and scatter plots showed distinct bifurcations, indicating that no co-localization existed (Figure 10A). Moreover, Pearson's correlation and Overlap coefficients of transferrin with LCDV (0.022, and 0.87), VDAC2 (0.009, and 0.87), and RACK1 (0.021, and 0.87) (Figure 10B) were significantly lower than those of CTB with LCDV, VDAC2, and RACK1 (Figure 9B), suggesting that LCDV, VDAC2, and RACK1 did not co-localize with transferrin, and that LCDV might adopt a different entry pathway from transferrin.

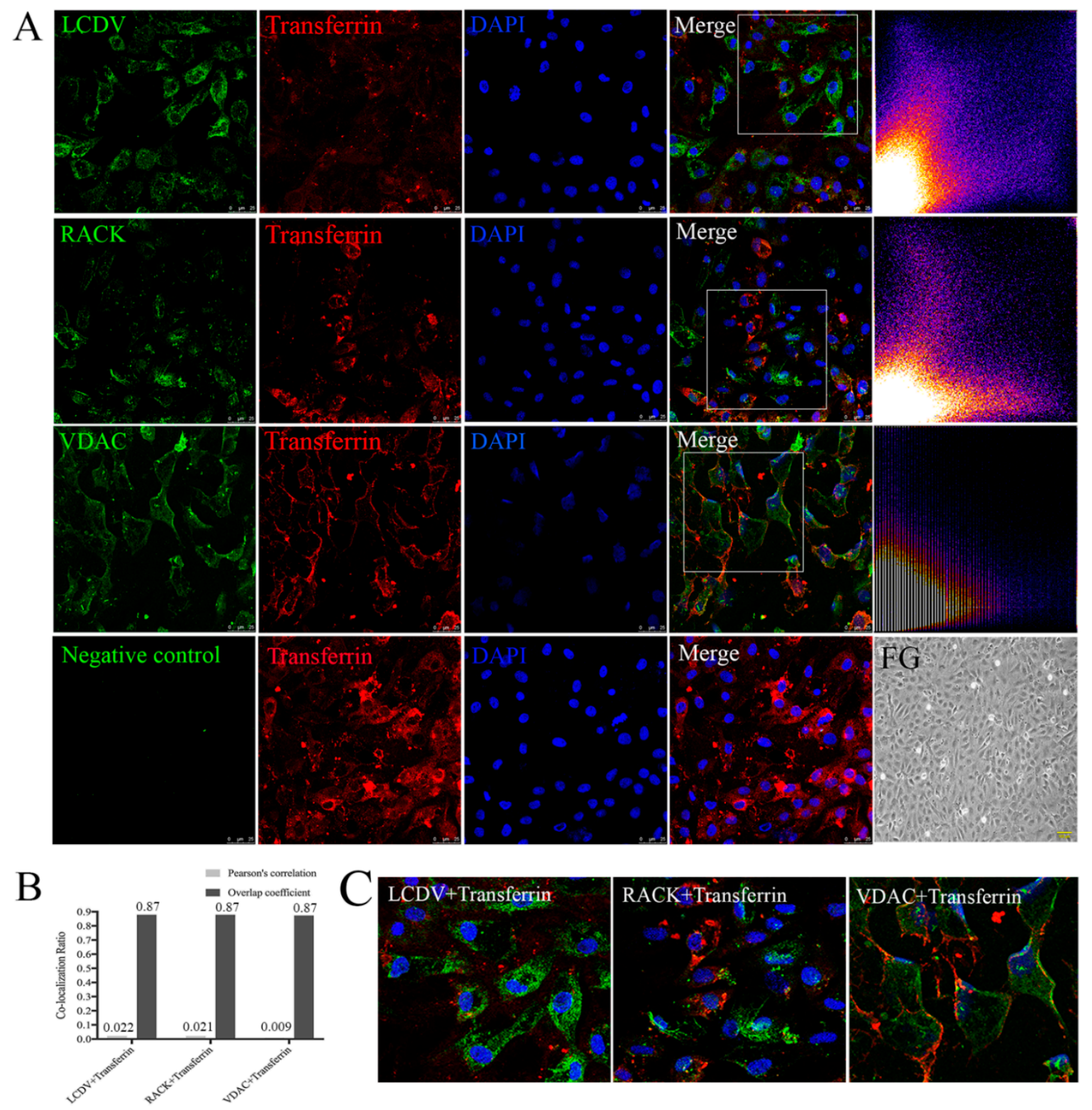

Figure 10. LCDV, VDAC2, and RACK1 do not co-localize with transferrin on FG cells. (A) The co-localization of LCDV, VDAC2, and RACK1 with transferrin analyzed by confocal microscopy; scatter plots represent the co-localization analysis of the merged images using ImageJ software, distinct bifurcations of the scattered blots indicated no co-localization existing, bars $=25 \mu \mathrm{m}$. Uninfected FG cells were shown as a control, bars $=100 \mu \mathrm{m}$. (B) Pearson's correlation and overlap coefficients of the merged images analyzed by ImageJ software. (C) Higher magnification on framed areas of merged figures in (A). Rabbit pre-immune serum instead of primary antibody served as a negative control. LCDV and transferrin were inoculated to FG cells at $22{ }^{\circ} \mathrm{C}$ for $2 \mathrm{~h}$. 


\subsection{Co-Localization of LCDV, VDAC2, and RACK1 with Caveolin}

Co-localization analysis of LCDV, VDAC2, and RACK1 with caveolin (a marker protein of caveolae-mediated endocytosis) using confocal microscopy revealed extensive LCDV-, VDAC2-, and RACK1-positive green signals in FG cell membranes and cytoplasm, accompanied by widely distributed caveolin-positive red signals at $2 \mathrm{~h}$ post LCDV infection; merged images of caveolin with LCDV, VDAC2, and RACK1 exhibited many yellow co-localization signals (Figure 11A,C). We further analyzed the merged images of LCDV, VDAC2, and RACK1 with caveolin using ImageJ software, and no bifurcations were observed in the scatter plots, indicating that co-localization existed (Figure 11A). The values of Pearson's correlation and overlap coefficients for caveolin with LCDV (0.15 and 0.89), VDAC2 (0.13 and 0.89), and RACK1 (0.13 and 0.89) (Figure 11B) were much higher than those of transferrin with LCDV, VDAC2, and RACK1 (Figure 10B). Therefore, caveolin co-localized with LCDV, VDAC2, and RACK1, and LCDV entry into FG cells was dependent on caveolae, mediated by VDAC2 and RACK1 receptor proteins.

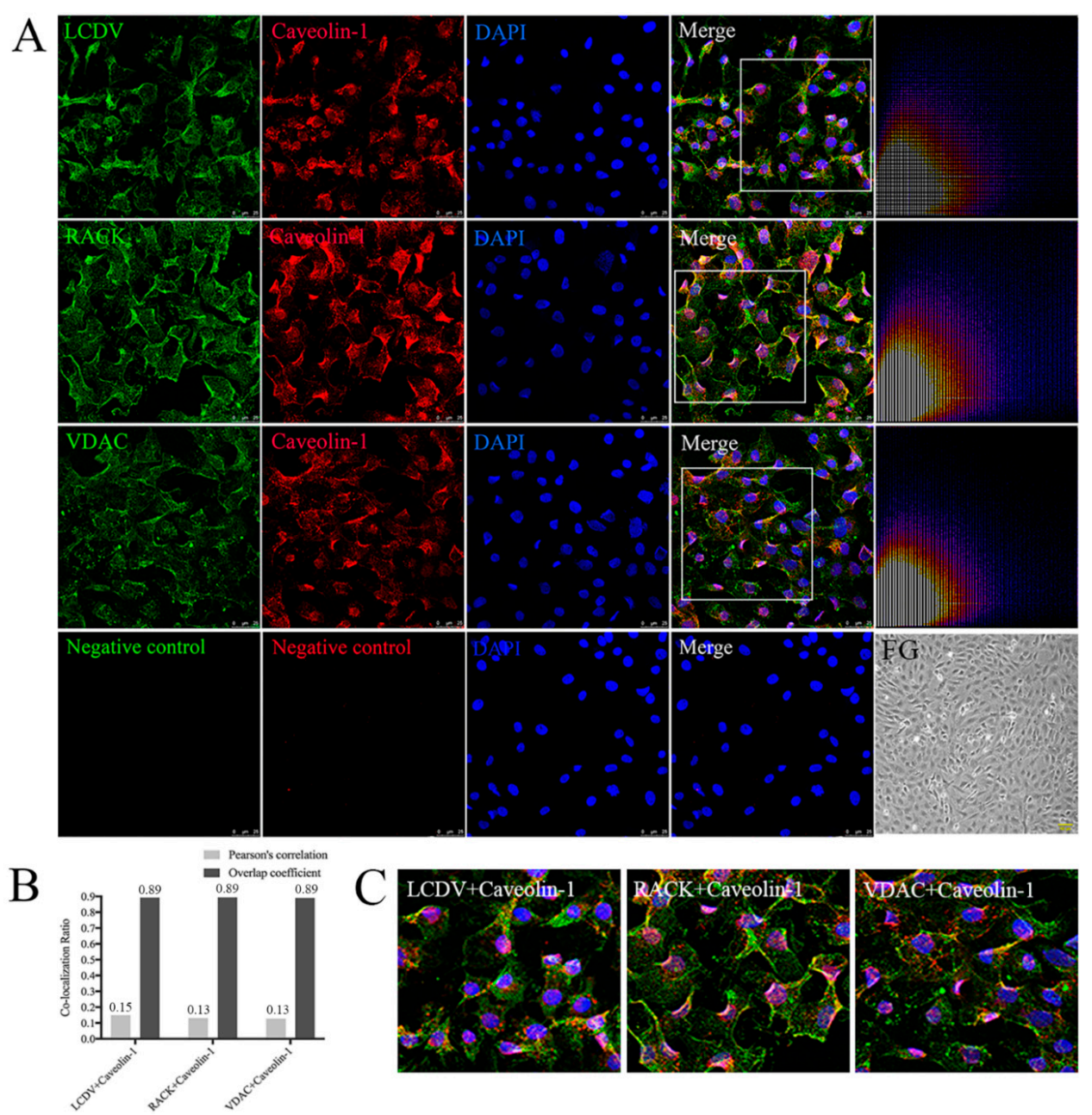

Figure 11. Co-localization of LCDV, VDAC2, and RACK1 with caveolin-1. (A) The co-localization of LCDV, VDAC2, and RACK1 with caveolin-1 analyzed by confocal microscopy; scatter plots represent the co-localization analysis of the merged images using ImageJ software, the diagonal shape of the scattered blots indicated a high level of co-localization, bars $=25 \mu \mathrm{m}$. Uninfected FG cells were shown as a control, bars $=100 \mu \mathrm{m}$. (B) Pearson's correlation and overlap coefficients of the merged images analyzed by ImageJ software. (C) Higher magnification on framed areas of merged figures in (A). Rabbit pre-immune serum paired with mouse pre-immune serum instead of primary antibodies served as a negative control. The virus inoculation was conducted at $22^{\circ} \mathrm{C}$ for $2 \mathrm{~h}$. 


\section{Discussion}

Viruses enter host cells by fusion, permeation, or endocytic vesicle discharge and exit them by budding or membrane disruption [46]. Although some viruses can penetrate directly into the cytoplasm, most viruses are transported across the plasma membrane through an endocytosis pathway and then transferred to other intracellular organs [47]. An understanding of the endocytosis pathway is critical for elucidating viral infection mechanism and developing antiviral agents. Iridoviruses are capable of infecting invertebrates and poikilothermic vertebrates, causing great economic losses in the aquaculture industry and showing a significant threat to global biodiversity $[43,44]$; however, the molecular mechanism underlying iridovirus entry into cells is not well understood. Comparatively, we know more about the entry pathway of the genus Ranavirus. Frog virus 3 (FV3), which is a type species of the genus Ranavirus and recognized as a model for iridoviruses, enters into mammalian cells (BHK-21) via the clathrin-mediated endocytosis [48], while tiger frog virus (TFV) enters into HepG2 cells via the caveola-mediated endocytosis pathway in a pH-dependent manner [49], and SGIV enters into the grouper spleen (GS) cells by clathrin-mediated endocytosis and micropinocytosis [45]. Among iridoviruses, viruses in the genus Lymphocystivirus, Megalocytivirus, and Ranavirus can infect teleost fish. It is found that ISKNV (the genus Megalocytivirus) also enters host cells via caveolae-dependent endocytosis [35]. However, no studies of the viral receptor proteins involved in the entry of SGIV and ISKNV have been reported [35,46]. In LCDV infection, we previously observed that the LCDV $32 \mathrm{kDa}$ VAP interacts with VDAC2 and RACK1 receptors to initiate virus infection. VDAC2/RACK1 knockdown through siRNA significantly reduced LCDV copy numbers, whereas VDAC2/RACK1 expression on LCDV-nonpermissive EPC conferred susceptibility to LCDV infection [15]. The LCDV $32 \mathrm{kDa}$ VAP is encoded by the ORF038 gene of LCDV isolated in China (LCDV-C) [14,50], and the LCDV-C ORF038 gene had homologues with genes encoding SGIV VP19 and rana grylio virus envelope protein $2 \mathrm{~L}[50,51]$. In the present study, we found that LCDV enters FG cells via caveolae-mediated endocytosis facilitated by VDAC2 and RACK1 receptors, relying on dynamin and microtubules in a $\mathrm{pH}$-independent manner, but clathrin-mediated endocytosis and macropinocytosis are not involved.

Caveolin and clathrin are specific biomarkers of caveolae-mediated endocytosis and clathrin-mediated endocytosis, respectively [21,34], while dynamin plays an important role in both endocytosis pathways [35]. Clathrin is assembled on the inside face of the plasma membrane to form a CCP [52]. Caveolins, a family of integral membrane proteins, are the structural proteins of caveolae [16], caveolin and dynamin shows a significant colocalization on plasmalemmal caveolae in lung endothelial cells [19]. We determined that the expression levels of caveolae, clathrin, and dynamin in FG cells were similar, using specific anti-caveolae, -clathrin, and -dynamin polyclonal antibodies evaluated by ELISA, IFA, and FACS analysis. Cellular membrane cholesterol is a constituent of caveolae and may be involved in different stages of the virus life cycle $[33,53]$. To address the role of cellular membrane cholesterol in LCDV infection, we eliminated FG cell cholesterol with $\mathrm{M} \beta C D$ prior to and post LCDV infection, respectively. LCDV entry was only severely inhibited by $M \beta C D$ treatment before virus infection, suggesting that cholesterol is important for the endocytosis of LCDV, while the subsequent LCDV life cycle, such as internalization or uncoating, might be independent of cholesterol. By contrast, in classic swine fever virus, removal of cell membrane cholesterol post infection significantly inhibits virus egression [53]. Caveolae-mediated endocytosis depends on cholesterol, but cholesterol consumption may cause acute effects and affect caveolae-independent endocytosis indirectly. Cholesterol in cellular membranes is essential for productive infection of African swine fever virus and classical swine fever virus, although they enter host cells via clathrin-mediated endocytosis $[54,55]$; cholesterol dependence is therefore not equivalent to caveolae dependence. In this study, the disruption of caveolae-mediated endocytosis by the cholesterol-binding reagents nystatin, filipin III, the tyrosine kinase inhibitor genistein, and the PKC activation inhibitor PMA severely impaired LCDV entry. LCDV-positive cells and copy numbers significantly decreased after treatment of reagents in various concentrations. All these results reveal that caveolae-mediated endocytosis depended on cholesterol. However, no clear dose-dependent inhibitory effect was observed in our 
study, which was not consistent with the results for ISKNV [35]; although we used similar reagent concentrations. This might be because of the difference in cells and virus species, or proportions of cell numbers and reagent concentrations, so more studies are needed. Furthermore, the disruption of caveolae-mediated endocytosis was verified by the internalization of CTB, which enters cells via caveolae-mediated endocytosis [41]. Meanwhile, LCDV copy numbers were significantly reduced in caveolin-1 knockdown FG cells, supporting the concept that LCDV entry into FG cells proceeds via caveolae-mediated endocytosis, as caveolin-1 is important for caveolae formation and scission [56]. However, with little inhibition of caveolin gene transcription, there was significant inhibition of caveolin protein expression, which might be because the reduction of target protein needed more time than its gene, or there may exist an optimal time point that the expression of gene and protein reduced simultaneously. Further research also is required in the future. Dynamin and microtubules play important roles in caveolae-mediated endocytosis, with dynamin participating in the scission of caveolae and microtubules acting as tracks for endocytic vesicle movement [35]. When we disrupted dynamin and microtubules using specific reagents, LCDV entry was significantly inhibited, and LCDV copy numbers were reduced after dynamin expression was knocked down. Similar results were also obtained for enterovirus 71, the virus RNA was significantly blocked in Jurkat T and PSGL-1-L929 cells when disturbing caveolar endocytosis by caveolin-1 siRNA [57]. It is possible for siRNAs to produce differences in the specific silencing of a target gene in different experiments; therefore, a more specific and stable knockout technique, such as the Crispr-Cas system, might be more effective in further research. However, the results in this study reveal that LCDV entry occurs via caveolae-mediated endocytosis and is dependent on dynamin and microtubules.

Clathrin-mediated endocytosis and macropinocytosis are two other important endocytosis pathways for viruses $[40,58]$. Virus entry via clathrin-mediated endocytosis usually depends on $\mathrm{pH}[45,55]$; however, entry of enterovirus 71 , which adopts caveolae-mediated endocytosis, is also dependent on intracellular $\mathrm{pH}$ [57]. Both caveolae-mediated and clathrin-mediated endocytosis are dependent on dynamin, while macropinocytosis is independent of dynamin $[28,59]$. Some viruses may adopt more than one endocytosis pathways, such as influenza A virus, which usually enters cells via clathrin-mediated endocytosis, but in some cases can activate macropinocytosis $[60,61]$. In the present study, the ability of LCDV to infect FG cells was not affected by disruption of cellular low-pH conditions, clathrin-mediated endocytosis, or macropinocytosis, because the percentages of LCDV positive cells and virus copy numbers were not obviously decreased as compared with negative control, indicating that LCDV entry is $\mathrm{pH}-$, clathrin-, and macropinocytosis-independent. The disruption of clathrin-mediated endocytosis was verified by the internalization of transferrin, which enters cells via clathrin-mediated endocytosis [42]. Besides, LCDV copy numbers were not decreased when clathrin expression in FG cells was knocked down, further indicating that LCDV entry is independent of clathrin-mediated endocytosis. However, some viruses may adopt different endocytosis pathways when entering different types of cells, such as enterovirus 71 (EV71), which enters human rhabdomyosarcoma (RD) cells via clathrin-mediated endocytosis, but activate caveolar endocytosis when infect Jurkat T and mouse L929 cells [57]. Since LCDV could infect other cell types, such as flounder embryo cells [62], understanding whether LCDV adopt the same endocytosis pathway in these cells requires further research.

When invading host cells, viruses first bind to cellular receptor proteins, and the process of entry mediated by receptor proteins is then initiated [23,63]. Viruses may adopt distinct entry pathways due to differences in receptor proteins $[57,64-66]$. For viruses that enter via caveolae-mediated endocytosis, receptor proteins are usually abundant in the caveolae of susceptible cells [67]. VDAC2 and RACK1 are widely distributed in caveolae [16-21], and VDAC2 and RACK1 knockdown or blocking inhibits LCDV infection of FG cells [15]. To elucidate the roles of VDAC2 and RACK1 in LCDV entry, we confirmed that LCDV could co-localize with VDAC2 and RACK1, and CTB also co-localized with VDAC2 and RACK1, while LCDV partially co-localized with CTB, indicating that VDAC2 and RACK1 mediate LCDV infection, and CTB might co-localize with VDAC2 and RACK1 during LCDV entry, even though 
the receptor protein for CTB in caveolae is ganglioside [68]. This might be because CTB assembles with VDAC2 and RACK1 in the caveolae, and LCDV might be in competition with CTB since they all adopt caveolae-mediated endocytosis. However, we detected no co-localization of transferrin with LCDV, VDAC2, or RACK1, suggesting that the LCDV entry pathway is different from that of transferrin, which is dependent on clathrin-mediated endocytosis; therefore, co-localization analysis of LCDV and clathrin was not performed in this study. Caveolin-1 was co-localized with LCDV, VDAC2, and RACK1, and we suggest that VDAC2 and RACK1 might assemble in caveolae to mediate the entry of LCDV via caveolae-mediated endocytosis, since caveolin-1 participates in the formation of caveolae where VDAC2 and RACK1 are widely distributed [16-20,23,34]. There may be differences in the timing and manner in which these two receptors work, and the specific roles of the two receptors in LCDV entry needs to be further clarified.

Together, our results support a model of LCDV entry via the caveolae-mediated endocytosis pathway facilitated by viral receptors VDAC2 and RACK1 (Figure 12). We propose the following model: the virus first interacts with cellular receptors VDAC2 and RACK1 on the FG cell surface and is then internalized into caveolae, which are primarily composed of cholesterol and caveolin-1; virus-receptor interaction activates the caveolae-mediated endocytosis pathway and the virus is further internalized. RACK1 might also function as a scaffolding protein to enrich signaling molecules. PKC and VDAC2 might also participate in the apoptotic signaling pathway during LCDV internalization [19,20,69], but the specific mechanism here needs more studies. Dynamin forms a ring to pinch off the caveolae, and the virus in a caveolae-coated vesicle is transferred into cells, moving along microtubules. Uncoating is initiated and viral nucleic acid is released when the vesicle arrives at its final destination. Since the definition of caveolae-mediated endocytosis has been revised in previous study [70], more studies of the interaction of the two viral receptors with caveolin-1 in LCDV entry are required to further modify the hypothetical model.

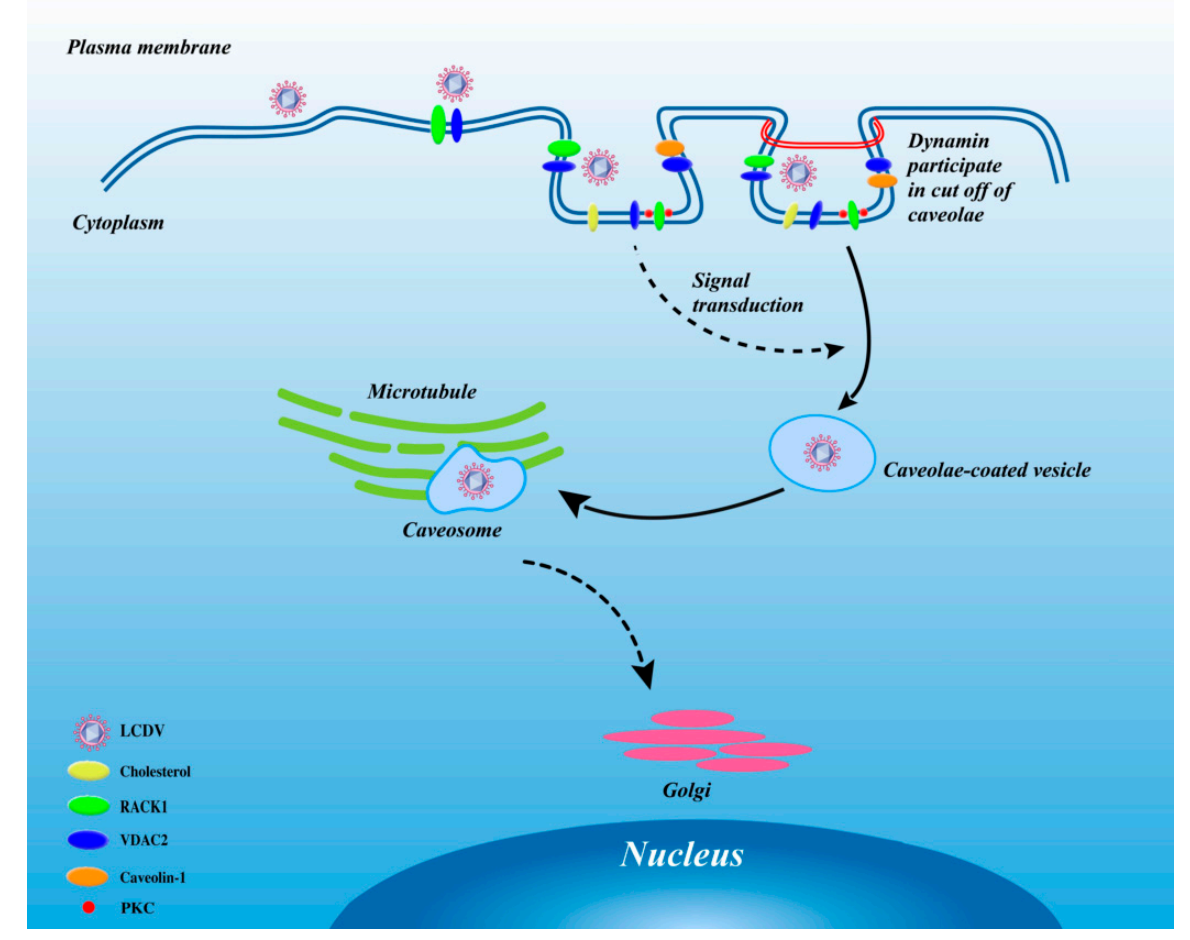

Figure 12. Model of LCDV entry via the caveolae-mediated endocytosis pathway facilitated by viral receptors. Solid arrow represented the LCDV entry steps has been proved in the present study, and dotted arrow represented potential steps basing on other published research. 
In conclusion, we confirmed that LCDV enters FG cells via caveolae-mediated endocytosis facilitated by VDAC2 and RACK1 receptors, relying on dynamin and microtubules in a cholesterol-dependent and $\mathrm{pH}$-independent manner; clathrin-mediated endocytosis and the macropinocytosis pathway are not involved. The LCDV endocytosis pathway is similar to that of ISKNV and TFV, which also use caveolae-mediated endocytosis [35,49], but TFV entry is pH dependent [35]; In contrast, FV3 enters cells via the clathrin-mediated endocytic pathway [48], and SGIV uses clathrin-mediated endocytosis and micropinocytosis [45]. This study of the LCDV entry pathway not only allows for further elucidation of the molecular mechanism of LCDV infection and provides potential for the development of antiviral agents, but also expands our understanding of iridovirus pathogenesis.

\section{Materials and Methods}

\subsection{Ethics Statement}

The present study was conducted in strict accordance with the recommendations in the Guide for the Use of Experimental Animals of Ocean University of China. The protocols for animal care and handling were approved by the Institutional Animal Care and Use Committee of the Ocean University of China (Permit Number: 20151201, offer date: 2015. 12. 01). All efforts were dedicated to minimizing suffering.

\subsection{Cells, Virus and Antibodies}

FG cells were cultured in Minimal Essential Medium (MEM) (Gibco, CA, USA) supplemented with $10 \%$ fetal bovine serum (FBS) (Gibco, Grand Island, CA, USA), $100 \mathrm{IU} / \mathrm{mL}$ penicillin and $100 \mu \mathrm{g} / \mathrm{mL}$ streptomycin (Gibco, Grand Island, CA, USA), and cultivated at $22{ }^{\circ} \mathrm{C}$ with $2 \% \mathrm{CO}$. FBS was reduced to $2 \%$ in maintenance medium post LCDV infection. Virus strain LCDV-HD (GenBank accession number: DQ279090) was purified in previous studies and stored at $-80^{\circ} \mathrm{C}[13,14]$.

Rabbit anti-LCDV 32 kDa VAP polyclonal antibody, mouse anti-32 kDa VAP MAb, rabbit anti-RACK1 polyclonal antibody, and rabbit anti-VDAC2 polyclonal antibody were produced in the authors' laboratory [13-15]. Alexa Fluor 647 conjugated goat anti-mouse or -rabbit Ig, Alexa Fluor 488 conjugated goat anti-mouse or -rabbit Ig, and Alexa Fluor 647 conjugated CTB (recombinant) or transferrin from human serum were purchased from Thermo Fisher (Waltham, MA, USA).

\subsection{Production and Specificity Analysis of Mouse Anti-Clathrin, Anti-Caveolin, and Anti-Dynamin Polyclonal Antibodies}

Mouse anti-clathrin, anti-caveolin, and anti-dynamin polyclonal antibodies were obtained by immunizing mice with polypeptides designed and synthesized by Genscript (Nanjing, China). Peptide sequences of clathrin, caveolin-1, and dynamin are listed in Table 1. For the first intraperitoneal immunization, $200 \mathrm{mg}$ KLH-conjugated polypeptide diluted in phosphate-buffered saline (PBS) was emulsified with equal volume of complete Freund's adjuvant (Sigma, St. Louis, MO, USA, 1:1). Two weeks later, a booster immunization was performed by administering $200 \mathrm{mg}$ KLH-conjugated polypeptide emulsified with incomplete Freund's adjuvant (Sigma, St. Louis, MO, USA, 1:1) through intraperitoneal injection. Mice were thereafter given two booster immunizations with $100 \mathrm{mg}$ KLH-conjugated polypeptide through caudal vein injection at one-week intervals. Three days after the last immunization, blood was obtained and placed at room temperature for $1 \mathrm{~h}$ and then at $4{ }^{\circ} \mathrm{C}$ overnight before centrifugation at $10,000 \times g$ for $30 \mathrm{~min}$. The supernatant was collected and stored at $-80^{\circ} \mathrm{C}$ until use. The specificity of mouse anti-clathrin, anti-caveolin, and anti-dynamin polyclonal antibodies was determined by ELISA, FACS, and IFA. 
Table 1. Primers, siRNAs, and peptides used in this study.

\begin{tabular}{|c|c|c|}
\hline Primer/siRNA/Peptide & Primer Sequence $\left(5^{\prime}-3^{\prime}\right)$ & Use \\
\hline qCaveolin-F & GGACCCCAAGCACATAAACG & RT-PCR (caveolin mRNA expression) \\
\hline qCaveolin-R & GGACAGGATGGCGAAGAAGAT & RT-PCR (caveolin mRNA expression) \\
\hline qClathrin-F & CTCGGGTATCATTGGGGTCA & RT-PCR (clathrin mRNA expression) \\
\hline qClathrin-R & GACGGATGGTGTCTGGGGTA & RT-PCR (clathrin mRNA expression) \\
\hline qDynamin-F & ACGCCCTGTCTCAAATGTATCG & RT-PCR (dynamin mRNA expression) \\
\hline qDynamin-R & AAGCCTATGAAGTCCTCGTGGTT & RT-PCR (dynamin mRNA expression) \\
\hline beta-actin-F & CACTGTGCCCATCTACGAG & RT-PCR (internal control) \\
\hline beta-actin- $\mathrm{R}$ & CCATCTCCTGCTCGAAGTC & RT-PCR (internal control) \\
\hline LCDV-038F & TCTTGTTCAGCATTTACTTCTCGGC & RT-PCR (LCDV copy number) \\
\hline LCDV-038R & TCTTCTCСTTTAGATGATTTCCC & RT-PCR (LCDV copy number) \\
\hline Clathrin-siRNA & GCAACCAAAUGUUCACCAATT & RNA interference assay \\
\hline Caveolin-siRNA & CCUUCACCGUCACCAAGUATT & RNA interference assay \\
\hline Dynamin-siRNA & GCCCGUAGACAUUGAGCAUTT & RNA interference assay \\
\hline NC-siRNA & UUCUCCGAACGUGUCACGUTT & RNA interference assay \\
\hline Clathrin peptide & MADPNTPIRRPISAC & $\begin{array}{l}\text { Production of mouse polyclonal } \\
\text { antibody against clathrin }\end{array}$ \\
\hline Caveolin-1 peptide & NIYKPNNKDMDNDSC & $\begin{array}{l}\text { Production of mouse polyclonal } \\
\text { antibody against caveolin-1 }\end{array}$ \\
\hline Dynamin peptide & CPGVPRRPAPRRNQW & $\begin{array}{l}\text { Production of mouse polyclonal } \\
\text { antibody against dynamin }\end{array}$ \\
\hline
\end{tabular}

For ELISA, 96-well microplates were coated with $20 \mu \mathrm{g}$ polypeptide per well and incubated overnight at $4{ }^{\circ} \mathrm{C}$. The wells were washed three times with PBST (PBS containing 0.05\% Tween-20, v/v) and then blocked with $4 \%$ bovine serum albumin (BSA, Sigma, St. Louis, MO, USA) at $37^{\circ} \mathrm{C}$ for $2 \mathrm{~h}$. After washing as above, the polyclonal antibodies diluted from 1:100 to 1:6400 in PBS were added as a primary antibody and AP-conjugated goat-anti-mouse Ig (Sigma, St. Louis, MO, USA) diluted 1:5000 in PBS was used as secondary antibody. After washing with PBST, $100 \mu \mathrm{L}$ substrate solution ( $1 \%$ diethanolamine, $0.5 \mathrm{mM} \mathrm{MgCl}_{2}, v / v, \mathrm{pH} 9.8$ ) containing $0.1 \%$ p-nitrophenyl phosphate (pNPP, Sigma, St. Louis, MO, USA) was added to each well, and absorbance was measured with an automatic ELISA reader (Molecular Devices, Union city, CA, USA) at $405 \mathrm{~nm}$. Mouse pre-immune serum instead of primary antibodies served as negative controls. The experiments were performed in triplicate.

For FACS, FG cells grown in $75 \mathrm{~cm}^{2}$ culture flasks were digested with trypsin and washed with PBS before fixing with $4 \%$ paraformaldehyde for $15 \mathrm{~min}$ at $22^{\circ} \mathrm{C}$. Subsequently, cells were incubated with the above mouse polyclonal antibodies separately at $37^{\circ} \mathrm{C}$ for $1.5 \mathrm{~h}$ and then washed three times with PBS. Cells were further incubated with Alexa Fluor 647 conjugated goat anti-mouse Ig at $37^{\circ} \mathrm{C}$ for $45 \mathrm{~min}$ and then washed as above. The percentage of clathrin-positive, caveolin-positive, and dynamin-positive FG cells was analyzed by FACS using flow cytometry (Beckman Counter, Fullerton, CA, USA) [71,72]. Mouse pre-immune serum instead of primary antibodies served as negative controls. Three replicates were performed.

For IFA, FG cells were seeded on circular coverslips in 24-well plates and fixed with $4 \%$ paraformaldehyde as above. Cells were then washed three times with PBS and incubated with the above mouse polyclonal antibodies separately at $37^{\circ} \mathrm{C}$ for $1.5 \mathrm{~h}$. After washing three times with PBS, cells were further incubated with Alexa Fluor 647 conjugated goat anti-mouse Ig at $37^{\circ} \mathrm{C}$ for $1 \mathrm{~h}$ and washed again. Cell nuclei were visualized using 4,6-diamidino-2-phenylindole (DAPI, Invitrogen, San Diego, CA, USA) and clathrin, caveolin-1, and dynamin were detected by fluorescence microscopy (Olympus, Tokyo, Japan). Mouse pre-immune serum instead of primary antibodies served as negative controls. Three replicates were performed.

\subsection{Drug Treatment and Cytotoxicity Assay}

The chemical reagents used in this study were purchased from Sigma-Aldrich (St. Louis, MO, USA) and prepared according to [35,45,73]. Ammonium chloride $\left(\mathrm{NH}_{4} \mathrm{Cl}\right)(1,5,10,25,50 \mathrm{mM})$ and $\mathrm{CQ}(5,10,25,50,75 \mu \mathrm{M})$ diluted in distilled water were used to disrupt the low-pH condition of endosomes and lysosomes in FG cells. $\mathrm{M} \beta \mathrm{CD}(0.5,1,1.5,1.8,2 \mathrm{mM})$ diluted in dimethyl sulfoxide 
(DMSO) solution was used to disrupt lipid rafts by depleting cholesterol. Dynasore $(1,5,10,25,50 \mu \mathrm{M})$ and nocodazole $(1,2.5,5,7.5,10 \mu \mathrm{M})$ diluted in DMSO were used to disrupt cellular dynamin and microtubules, respectively. Sucrose $(100,150,200,250,300 \mathrm{mM})$ and CPZ $(1,5,10,25,35 \mu \mathrm{M})$ in distilled water served as inhibitory agents of CCP formation to disrupt clathrin-mediated endocytosis. For the depletion of caveolae-mediated endocytosis, filipin III $(1,5,10,25,50 \mu \mathrm{g} / \mathrm{mL})$ and nystatin $(5$, $10,25,50,100 \mu \mathrm{g} / \mathrm{mL})$ in DMSO were used to bind cholesterol, genistein $(2.5,5,10,25,50 \mu \mathrm{M})$ and PMA $(0.1,0.5,1,5,10 \mu \mathrm{M})$ in DMSO was used to inhibit tyrosine kinase and PKC, respectively. To inhibit the macropinocytosis pathway, wortmannin $(5,10,25,50,100 \mu \mathrm{M})$ as a PI3K inhibitor and EIPA $(1,5,10$, $20,40 \mu \mathrm{M})$ that blocks $\mathrm{Na}^{+} / \mathrm{H}^{+}$exchange, diluted in DMSO, were used.

To disrupt the endocytosis pathway for LCDV entry, $\mathrm{NH}_{4} \mathrm{Cl}, \mathrm{CQ}, \mathrm{M} \beta \mathrm{CD}$, dynasore, nocodazole, sucrose, CPZ, filipin III, nystatin, genistein, PMA, wortmannin and EIPA at different concentrations were used to treat FG cells prior to LCDV infection. FG cells grown in 25 and $75 \mathrm{~cm}^{2}$ culture flasks with 90\% confluence were washed three times with PBS and treated with different concentrations of reagents at $22{ }^{\circ} \mathrm{C}$ for $1 \mathrm{~h}$. Cells were then inoculated with LCDV at 4 median tissue culture infective dose $\left(\mathrm{TCID}_{50} / \mathrm{mL}\right)$ as described previously $[11,74]$ for another $1 \mathrm{~h}$ in the continued presence of the reagents at $22{ }^{\circ} \mathrm{C}$ with $2 \% \mathrm{CO} 2 . \mathrm{M} \beta \mathrm{CD}$ with various concentrations was used to treat $\mathrm{FG}$ cells at $22^{\circ} \mathrm{C}$ for $1 \mathrm{~h}$ prior to or post LCDV infection in the continued presence of reagent. Cells were washed once with citrate buffer ( $40 \mathrm{mM}$ sodium citrate, $10 \mathrm{mM} \mathrm{KCl}, 135 \mathrm{mM} \mathrm{NaCl}$, pH 3.1) for $50 \mathrm{~s}$ to inactivate the virus and three times with PBS to remove residual citrate buffer [35,45], and then cultivated in $2 \%$ maintenance medium for $24 \mathrm{~h}$. FG cells treated with corresponding solvents instead of the reagents served as negative controls. Cells grown in $75 \mathrm{~cm}^{2}$ culture flasks were digested using trypsin, centrifuged at $800 \times \mathrm{g}$ for $5 \mathrm{~min}$, and then washed three times with PBS. After fixed with $4 \%$ paraformaldehyde for $15 \mathrm{~min}$ at room temperature and washing three times with PBS, cells were incubated with rabbit anti-LCDV $32 \mathrm{kDa}$ VAP polyclonal antibody (1:500) for $1.5 \mathrm{~h}$, followed by Alexa Fluor 647 conjugated goat anti-rabbit Ig for $45 \mathrm{~min}$ at $37^{\circ} \mathrm{C}$. After washing again, the percentage of LCDV-infected FG cells was detected by FACS. FG cells grown in $25 \mathrm{~cm}^{2}$ culture flasks were digested and centrifuged, the DNA of these cells was extracted using a TIANamp Marine Animals DNA Kit (Qiagen, Hilden, Germany) following the manufacturer's instructions, and LCDV copy numbers were detected by qPCR. The qPCR reaction conditions were as follows: $10 \mathrm{~min}$ at $95^{\circ} \mathrm{C}$, followed by 45 cycles of $10 \mathrm{~s}$ at $95^{\circ} \mathrm{C}$, $10 \mathrm{~s}$ at $55^{\circ} \mathrm{C}$, and $20 \mathrm{~s}$ at $72{ }^{\circ} \mathrm{C}$. LCDV copy numbers were calculated using a standard curve according to $\mathrm{Ct}$ values as described previously [13].

To confirm whether clathrin-mediated endocytosis in FG cells could be disrupted by specific chemical reagents, cells were treated with $\mathrm{NH}_{4} \mathrm{Cl}(5 \mathrm{mM}), \mathrm{CQ}(10 \mu \mathrm{M})$, sucrose $(150 \mathrm{mM})$, or CPZ $(10 \mu \mathrm{M})$ at $22^{\circ} \mathrm{C}$ for $1 \mathrm{~h}$, and then incubated with Alexa Fluor 647 conjugated transferrin $(10 \mu \mathrm{g} / \mathrm{mL})$ at $22^{\circ} \mathrm{C}$ for $1 \mathrm{~h}$. Similarly, FG cells were incubated with Alexa Fluor 647 conjugated CTB $(20 \mu \mathrm{g} / \mathrm{mL})$ after treatment with $\mathrm{M} \beta \mathrm{CD}(1.5 \mathrm{mM})$, nystatin $(25 \mu \mathrm{g} / \mathrm{mL})$, genistein $(10 \mu \mathrm{M})$, or filipin III $(10 \mu \mathrm{g} / \mathrm{mL})$ to disrupt caveolae-mediated endocytosis. After washing cells with citrate buffer and PBS, the percentage of transferrin-positive and CTB-positive cells was detected by FACS. Finally, the internalization of transferrin and CTB to FG cells was observed under a fluorescence microscope (Olympus, Tokyo, Japan). FG cells treated with the corresponding solvent instead of reagents served as negative controls.

MTT assay was used to detect the influence of chemical reagents on FG cell viability. FG cells were seeded in 96-well plates and grown to a monolayer before incubating with different concentrations of reagents for $2 \mathrm{~h}$. Reagents were then removed and cells were washed with citrate buffer and PBS. Cells were incubated with $50 \mu \mathrm{L}$ MTT (Sigma, St. Louis, MO, USA) at $22{ }^{\circ} \mathrm{C}$ for $4 \mathrm{~h}$. Thereafter, the supernatant was removed and $150 \mu \mathrm{L}$ DMSO was added and incubated for $10 \mathrm{~min}$. Absorbencies were measured with an automatic ELISA reader (Molecular Devices, Union city, CA, USA) at $490 \mathrm{~nm}$.

\subsection{RNAi Knockdown of Clathrin, Caveolin-1, and Dynamin}

The clathrin, caveolin-1, and dynamin 2 in FG cells were knocked down by using siRNAs designed by Shanghai GenePharma Company (Shanghai, China). The siRNA sequences targeting clathrin, 
caveolin-1, and dynamin 2 and the control NC-siRNA are shown in Table 1. FG cells were grown in six-well plates, and siRNAs were separately transfected into FG cells using Lipofectamine 3000 reagent (Invitrogen, Carlsbad, CA, USA) according to the manufacturer's instructions. Briefly, $5 \mu \mathrm{L}$ $(20 \mu \mathrm{M})$ of siRNA and $3.25 \mu \mathrm{L}$ Lipofectamine 3000 reagent were diluted with $125 \mu \mathrm{L}$ opti-MEM (Gibco, Grand Island, CA, USA) separately, mixed and incubated for $20 \mathrm{~min}$ at room temperature. Another $2 \mathrm{~mL}$ opti-MEM was added before mixing with FG cells. After incubation for $6 \mathrm{~h}$, the supernatant was removed, and maintenance medium without penicillin or streptomycin was added. FG cells were collected at $48 \mathrm{~h}$ post transfection, and total RNA was extracted using RNAiso (Takara, Dalian, China) and reverse-transcribed into cDNA using a PrimeScript RT-PCR Kit (Takara, Dalian, China). Expression of clathrin, caveolin-1, and dynamin mRNA was detected by qPCR using primers listed in Table 1. Gene expression was calculated according to the $2^{-\Delta \Delta C t}$ method with the expression of $\beta$-actin as an internal control. Protein expressions of clathrin, caveolin-1, and dynamin were detected by IFA. Specifically, $48 \mathrm{~h}$ post transfection with siRNAs, FG cells were fixed with $4 \%$ paraformaldehyde for $15 \mathrm{~min}$ at room temperature and washed three times with PBS. Cells were then incubated with mouse anti-clathrin, anti-caveolin, and anti-dynamin polyclonal antibodies at $37^{\circ} \mathrm{C}$ for $1.5 \mathrm{~h}$, followed by incubation with Alexa Fluor 647 conjugated goat anti-mouse Ig at $37^{\circ} \mathrm{C}$ for $1 \mathrm{~h}$. FG cells were observed through a fluorescence microscope, and the value of mean fluorescence intensity of all cells in the field was measured using ImageJ software. Three group figures for each specific siRNA was analyzed.

To elucidate the influence of clathrin, caveolin-1, and dynamin knockdown on LCDV infection, FG cells were infected with LCDV particles at $22{ }^{\circ} \mathrm{C}$ for $1 \mathrm{~h}$ at $48 \mathrm{~h}$ post siRNA transfection. The cells were collected at $48 \mathrm{~h}$ post LCDV infection, and DNA was extracted using a TIANamp Marine Animals DNA Kit (Qiagen, Hilden, Germany). LCDV copy numbers were detected by qPCR and calculated using a standard curve according to $\mathrm{Ct}$ values as described above.

\subsection{Laser Scanning Confocal Immunofluorescence Microscopy}

To investigate the entry of LCDV mediated by VDAC2 and RACK1 receptors, the co-localization of LCDV with VDAC2 and RACK1, CTB with LCDV, VDAC2 and RACK1, transferrin with LCDV, VDAC2 and RACK1, and caveolin-1 with LCDV, VDAC2 and RACK1, respectively, was detected by laser scanning confocal immunofluorescence microscopy. The co-localization level of merged figures in each group was quantified into scattered blots, values of Pearson's correlation, and overlap coefficients by using ImageJ software, three merged figures were analyzed and the results of one merged figure were provided for each group. Pearson's correlation (-1.0-1.0): values less than 0 indicate the absence of co-localization; overlap coefficient (0-1.0): 0.5 indicates $50 \%$ of fluorescence in the selected channels was colocalized.

For the co-staining of LCDV with VDAC2 and RACK1, FG cells were grown to a monolayer on circular coverslips in 24-well plates and washed with PBS after removing the supernatant. Cells were then incubated with $100 \mu \mathrm{L} \mathrm{LCDV}$ at a concentration of $4 \mathrm{TCID}_{50} / \mathrm{mL}$ for $2 \mathrm{~h}$ at $22^{\circ} \mathrm{C}$. Following washes with citrate buffer and PBS, cells were fixed with $4 \%$ paraformaldehyde for 15 min at room temperature and incubated with mouse anti-LCDV $32 \mathrm{kDa}$ VAP MAbs (1:250) paired with rabbit anti-RACK1 polyclonal antibody (1:500) or rabbit anti-VDAC2 polyclonal antibody (1:500) as primary antibodies at $37^{\circ} \mathrm{C}$ for $1.5 \mathrm{~h}$. Thereafter, cells were washed with PBS and incubated with Alexa Fluor 488 conjugated goat anti-mouse Ig (1:500) paired with Alexa Fluor 647 conjugated goat anti-rabbit $\operatorname{Ig}$ (1:500) as secondary antibodies at $37^{\circ} \mathrm{C}$ for $1 \mathrm{~h}$. After washing with PBS, cell nuclei were stained blue using DAPI at $37^{\circ} \mathrm{C}$ for $15 \mathrm{~min}$. Cells were observed under a confocal laser scanning microscope (Leica, Wetzlar, Germany). Rabbit pre-immune serum paired with mouse pre-immune serum instead of primary antibodies served as a negative control.

For the co-localization of CTB with LCDV, VDAC2, and RACK1, as well as transferrin with LCDV, VDAC2, and RACK1, FG cells were incubated with $100 \mu \mathrm{L} L C D V$ and an equal volume of Alexa Fluor 647 conjugated CTB or transferrin for $2 \mathrm{~h}$ at $22^{\circ} \mathrm{C}$. After washing and being fixed as above, FG cells were incubated with rabbit anti-LCDV (1:500), anti-RACK1 (1:500), or anti-VDAC2 
(1:500) polyclonal antibody at $37^{\circ} \mathrm{C}$ for $1.5 \mathrm{~h}$, respectively, and then incubated with Alexa Fluor 488 conjugated goat anti-rabbit Ig at $37^{\circ} \mathrm{C}$ for $1 \mathrm{~h}$. For the co-localization of caveolin with LCDV, VDAC2, and RACK1, FG cells were incubated with mouse anti-caveolin polyclonal antibody (1:100) paired with rabbit anti-LCDV, anti-RACK1, or anti-VDAC2 polyclonal antibody (1:500) as primary antibodies. Subsequently, cells were incubated with Alexa Fluor 647 conjugated goat anti-mouse Ig (1:500) paired with Alexa Fluor 488 conjugated goat anti-rabbit $\operatorname{Ig}(1: 500)$ as secondary antibodies. After washing with PBS, cells were stained with DAPI to visualize nuclei and observed under a confocal laser scanning microscope. Rabbit pre-immune serum instead of primary antibodies, or rabbit pre-immune serum paired with mouse pre-immune serum instead of primary antibodies, served as a negative control.

\subsection{Statistical Analysis}

The statistical analysis of ELISA and qPCR was performed using Prism 7.0 and SPSS 20.0 software (Chicago, IL, USA). All data were expressed as mean \pm standard deviation. The qPCR data of each experimental group and control group were firstly analyzed by Levene's test for homogeneity of variance at a $5 \%$ significance level. If variances were considered to be equal, the data would be subjected to a two-sample $t$-test; if not, the Welch's $t$-test would be performed. Differences were considered statistically significant when $p<0.05$.

Supplementary Materials: Supplementary materials can be found at http://www.mdpi.com/1422-0067/21/13/ $4722 / s 1$.

Author Contributions: X.S. designed the research, analyzed the data and wrote the manuscript. Y.Z. performed the experiments and helped with data analysis and manuscript writing. J.Z. and X.T. helped with the experiments. J.X. and H.C. helped the reagent preparation and participated in data analysis. W.Z. designed the research and revised the manuscript. All authors have read and agree to the published version of the manuscript.

Funding: This study was supported by grants from the National Natural Science Foundation of China (31872599, 31730101, and 31672685), the National Key R\&D Program of China (2019YFD0900102), and Taishan Scholar Program of Shandong Province.

Conflicts of Interest: The authors declare that there are no conflicts of interest.

\section{References}

1. Berthiaume, L.; Alain, R.; Robin, J. Morphology and ultrastructure of lymphocystis disease virus, a fish iridovirus, grown in tissue culture. J. Virol. 1984, 135, 10-19. [CrossRef]

2. Schnitzler, P.; Handermann, M.; Szépe, O.; Darai, G. The primary structure of the thymidine kinase gene of fish lymphocystis disease virus. Virology 1991, 182, 835-840. [CrossRef]

3. Kitamura, S.-I.; Ko, J.-Y.; Lee, W.-L.; Kim, S.-R.; Song, J.-Y.; Kim, D.-K.; Jung, S.-J.; Oh, M.-J. Seasonal prevalence of lymphocystis disease virus and aquabirnavirus in Japanese flounder, Paralichthys olivaceus and blue mussel, Mytilus galloprovincialis. Aquaculture 2007, 266, 26-31. [CrossRef]

4. Hossain, M.; Kim, S.-R.; Kitamura, S.-I.; Kim, D.-W.; Jung, S.-J.; Nishizawa, T.; Yoshimizu, M.; Oh, M.-J. Lymphocystis disease virus persists in the epidermal tissues of olive flounder, Paralichthys olivaceus (Temminch \& Schlegel), at low temperatures. J. Fish Dis. 2009, 32, 699-703. [CrossRef] [PubMed]

5. Yan, X.-Y.; Wu, Z.-H.; Jian, J.-C.; Lu, Y.-S.; Sun, X.-Q. Analysis of the genetic diversity of the lymphocystis virus and its evolutionary relationship with its hosts. Virus Genes 2011, 43, 358-366. [CrossRef]

6. Sheng, X.; Wu, R.; Tang, X.; Xing, J.; Zhan, W. Tissue Localization of Lymphocystis Disease Virus (LCDV) Receptor-27.8 kDa and Its Expression Kinetics Induced by the Viral Infection in Turbot (Scophthalmus maximus). Int. J. Mol. Sci. 2015, 16, 26506-26519. [CrossRef]

7. Schnitzler, P.; Darai, G. Identification of the gene encoding the major capsid protein of fish lymphocystis disease virus. J. Gen. Virol. 1993, 74, 2143-2150. [CrossRef]

8. Huang, X.; Huang, Y.; Xu, L.; Wei, S.; Ouyang, Z.; Feng, J.; Qin, Q. Identification and characterization of a novel lymphocystis disease virus isolate from cultured grouper in China. J. Fish Dis. 2014, 38, 379-387. [CrossRef] 
9. Carballo, C.; Castro, D.; Borrego, J.J.; Manchado, M. Gene expression profiles associated with lymphocystis disease virus (LCDV) in experimentally infected Senegalese sole (Solea senegalensis). Fish Shellfish Immunol. 2017, 66, 129-139. [CrossRef] [PubMed]

10. Valverde, E.J.; Borrego, J.J.; Sarasquete, C.; Ortiz-Delgado, J.B.; Castro, D. Target organs for lymphocystis disease virus replication in gilthead seabream (Sparus aurata). Vet. Res. 2017, 48, 1-11. [CrossRef] [PubMed]

11. Wang, M.; Sheng, X.; Xing, J.; Tang, X.; Zhan, W. Identification of a $27.8 \mathrm{kDa}$ protein from flounder gill cells involved in lymphocystis disease virus binding and infection. Dis. Aquat. Org. 2011, 94, 9-16. [CrossRef] [PubMed]

12. Tong, S.-L.; Li, H.; Miao, H.-Z. The establishment and partial characterization of a continuous fish cell line FG-9307 from the gill of flounder Paralichthys olivaceus. Aquaculture 1997, 156, 327-333. [CrossRef]

13. Zhong, Y.; Fei, C.; Tang, X.; Zhan, W.; Sheng, X. A $32 \mathrm{kDa}$ viral attachment protein of lymphocystis disease virus (LCDV) specifically interacts with a $27.8 \mathrm{kDa}$ cellular receptor from flounder (Paralichthys olivaceus). J. Gen. Virol. 2017, 98, 1477-1488. [CrossRef] [PubMed]

14. Zhong, Y.; Tang, X.; Sheng, X.; Xing, J.; Zhan, W. Development and Characterization of Monoclonal Antibodies to the $32 \mathrm{kDa}$ Viral Attachment Protein of Lymphocystis Disease Virus and Their Neutralizing Ability in Vitro. Int. J. Mol. Sci. 2018, 19, 2536. [CrossRef] [PubMed]

15. Zhong, Y.; Tang, X.; Sheng, X.; Xing, J.; Zhan, W. Voltage-Dependent Anion Channel Protein 2 (VDAC2) and Receptor of Activated Protein C Kinase 1 (RACK1) Act as Functional Receptors for Lymphocystis Disease Virus Infection. J. Virol. 2019, 93, 1-19. [CrossRef] [PubMed]

16. Bàthori, G.; Parolini, I.; Tombola, F.; Szabò, I.; Messina, A.; Oliva, M.; De Pinto, V.; Lisanti, M.; Sargiacomo, M.; Zoratti, M. Porin Is Present in the Plasma Membrane Where It Is Concentrated in Caveolae and Caveolae-related Domains. J. Biol. Chem. 1999, 274, 29607-29612. [CrossRef] [PubMed]

17. Marin, R.; Ramírez, C.; Gonzalez, M.D.; González-Muñoz, E.; Zorzano, A.; Camps, M.; Alonso, R.; Díaz, M. Voltage-dependent anion channel (VDAC) participates in amyloid beta-induced toxicity and interacts with plasma membrane estrogen receptor $\alpha$ in septal and hippocampal neurons. Mol. Membr. Biol. 2007, 24, 148-160. [CrossRef] [PubMed]

18. De Pinto, V.; Messina, A.; Lane, D.; Lawen, A. Voltage-dependent anion-selective channel (VDAC) in the plasma membrane. FEBS Lett. 2010, 584, 1793-1799. [CrossRef]

19. Smart, E.J.; Graf, G.A.; McNiven, M.A.; Sessa, W.C.; Engelman, J.A.; Scherer, P.E.; Okamoto, T.; Lisanti, M.P. Caveolins, Liquid-Ordered Domains, and Signal Transduction. Mol. Cell. Biol. 1999, 19, 7289-7304. [CrossRef]

20. Mochly-Rosen, D.; Gordon, A.S. Anchoring proteins for protein kinase C: A means for isozyme selectivity. FASEB J. 1998, 12, 35-42. [CrossRef]

21. Mercer, J.; Schelhaas, M.; Helenius, A. Virus Entry by Endocytosis. Annu. Rev. Biochem. 2010, 79, $803-833$. [CrossRef]

22. Ou, X.; Liu, Y.; Lei, X.; Li, P.; Mi, D.; Ren, L.; Guo, L.; Guo, R.; Chen, T.; Hu, J.; et al. Characterization of spike glycoprotein of SARS-CoV-2 on virus entry and its immune cross-reactivity with SARS-CoV. Nat. Commun. 2020, 11, 1620. [CrossRef]

23. Grove, J.; Marsh, M. The cell biology of receptor-mediated virus entry. J. Cell Biol. 2011, 195, 1071-1082. [CrossRef]

24. Yamauchi, Y.; Helenius, A. Virus entry at a glance. J. Cell Sci. 2013, 126, 1289-1295. [CrossRef] [PubMed]

25. Marsh, M.; Helenius, A. Virus entry into animal cells. Adv. Virus Res. 1989, 36, 107-151.

26. Robinson, M.S. Adaptable adaptors for coated vesicles. Trends Cell Biol. 2004, 14, 167-174. [CrossRef]

27. Pelkmans, L.; Fava, E.; Grabner, H.; Hannus, M.; Habermann, B.; Krausz, E.; Zerial, M. Genome-wide analysis of human kinases in clathrin- and caveolae/raft-mediated endocytosis. Nature 2005, 436, 78-86. [CrossRef]

28. Mousavi, S.A.; Malerod, L.; Berg, T.; Kjeken, R. Clathrin-dependent endocytosis. Biochem. J. 2004, 377, 1-16. [CrossRef] [PubMed]

29. Marsh, M.; Helenius, A. Virus Entry: Open Sesame. Cell 2006, 124, 729-740. [CrossRef] [PubMed]

30. Anderson, H.A.; Chen, Y.; Norkin, L.C. Bound simian virus 40 translocates to caveolin-enriched membrane domains, and its entry is inhibited by drugs that selectively disrupt caveolae. Mol. Biol. Cell 1996, 7, 1825-1834. [CrossRef] [PubMed]

31. Stang, E.; Kartenbeck, J.; Parton, R. Major histocompatibility complex class I molecules mediate association of SV40 with caveolae. Mol. Biol. Cell 1997, 8, 47-57. [CrossRef] 
32. Pelkmans, L.; Kartenbeck, J.; Helenius, A. Caveolar endocytosis of simian virus 40 reveals a new two-step vesicular transport pathway to the ER. Nat. Cell Biol. 2001, 3, 473-483. [CrossRef]

33. Patel, H.H.; Murray, F.; Insel, P.A. Caveolae as organizers of pharmacologically relevant signal transduction molecules. Annu. Rev. Pharmacol. 2008, 48, 359-391. [CrossRef] [PubMed]

34. Lisanti, M.P.; Tang, Z.; Scherer, P.E.; Kübler, E.; Koleske, A.J.; Sargiacomo, M. Caveolae, transmembrane signalling and cellular transformation. Mol. Membr. Biol. 1995, 12, 121-124. [CrossRef] [PubMed]

35. Guo, C.-J.; Wu, Y.-Y.; Yang, L.-S.; Yang, X.-B.; He, J.; Mi, S.; Jia, K.-T.; Weng, S.-P.; Yu, X.-Q.; He, J.; et al. Infectious Spleen and Kidney Necrosis Virus (a Fish Iridovirus) Enters Mandarin Fish Fry Cells via Caveola-Dependent Endocytosis. J. Virol. 2011, 86, 2621-2631. [CrossRef] [PubMed]

36. Simpson, C.; Yamauchi, Y. Microtubules in Influenza Virus Entry and Egress. Viruses 2020, 12, 117. [CrossRef] [PubMed]

37. Mercer, J.; Helenius, A. Virus entry by macropinocytosis. Nat. Cell Biol. 2009, 11, 510-520. [CrossRef]

38. Swanson, J.A. Shaping cups into phagosomes and macropinosomes. Nat. Rev. Mol. Cell Biol. 2008, 9, 639-649. [CrossRef]

39. Ghigo, É.; Kartenbeck, J.; Lien, P.; Pelkmans, L.; Capo, C.; Mege, J.-L.; Raoult, D. Ameobal Pathogen Mimivirus Infects Macrophages through Phagocytosis. PLoS Pathog. 2008, 4, e1000087. [CrossRef]

40. Rojek, J.M.; Perez, M.; Kunz, S. Cellular entry of lymphocytic choriomeningitis virus. J. Virol. 2008, 82, 1505-1517. [CrossRef]

41. Pelkmans, L.; Helenius, A. Endocytosis via caveolae. Traffic 2002, 3, 311-320. [CrossRef] [PubMed]

42. Mayle, K.M.; Le, A.M.; Kamei, D.T. The intracellular trafficking pathway of transferrin. Biochim. Biophys. Acta 2012, 1820, 264-281. [CrossRef] [PubMed]

43. Chinchar, V.G.; Yu, K.H.; Jancovich, J.K. The Molecular Biology of Frog Virus 3 and other Iridoviruses Infecting Cold-Blooded Vertebrates. Viruses 2011, 3, 1959-1985. [CrossRef] [PubMed]

44. Chinchar, V.G.; Waltzek, T.B. Ranaviruses: Not Just for Frogs. PLoS Pathog. 2014, 10, e1003850. [CrossRef]

45. Wang, S.; Huang, X.; Huang, Y.; Hao, X.; Xu, H.; Cai, M.; Wang, H.; Qin, Q. Entry of a Novel Marine DNA Virus, Singapore Grouper Iridovirus, into Host Cells Occurs via Clathrin-Mediated Endocytosis and Macropinocytosis in a pH-Dependent Manner. J. Virol. 2014, 88, 13047-13063. [CrossRef]

46. Chazal, N.; Gerlier, D. Virus Entry, Assembly, Budding, and Membrane Rafts. Microbiol. Mol. Biol. Rev. 2003, 67, 226-237. [CrossRef]

47. Smith, A.E.; Helenius, A. How Viruses Enter Animal Cells. Science 2004, 304, 237-242. [CrossRef]

48. Braunwald, J.; Nonnenmacher, H.; Tripier-Darcy, F. Ultrastructural and Biochemical Study of Frog Virus 3 Uptake by BHK-21 Cells. J. Gen. Virol. 1985, 66, 283-293. [CrossRef]

49. Guo, C.-J.; Liu, N.; Wu, Y.-Y.; Yang, X.-B.; Yang, L.-S.; Mi, S.; Huang, Y.-X.; Luo, Y.-W.; Jia, K.-T.; Liu, Z.-Y.; et al. Entry of Tiger Frog Virus (an Iridovirus) into HepG2 Cells via a pH-Dependent, Atypical, Caveola-Mediated Endocytosis Pathway. J. Virol. 2011, 85, 6416-6426. [CrossRef]

50. Zhang, Q.-Y.; Xiao, F.; Xie, J.; Li, Z.-Q.; Gui, J.-F. Complete Genome Sequence of Lymphocystis Disease Virus Isolated from China. J. Virol. 2004, 78, 6982-6994. [CrossRef]

51. He, L.-B.; Ke, F.; Wang, J.; Gao, X.-C.; Zhang, Q.-Y. Rana grylio virus (RGV) envelope protein 2L: Subcellular localization and essential roles in virus infectivity revealed by conditional lethal mutant. J. Gen. Virol. 2014, 95, 679-690. [CrossRef] [PubMed]

52. Cheng, C.Y.; Shih, W.L.; Huang, W.R.; Chi, P.I.; Wu, M.H.; Liu, H.-J. Bovine Ephemeral Fever Virus Uses a Clathrin-Mediated and Dynamin 2-Dependent Endocytosis Pathway That Requires Rab5 and Rab7 as Well as Microtubules. J. Virol. 2012, 86, 13653-13661. [CrossRef]

53. Zhang, Y.-N.; Liu, Y.-Y.; Xiao, F.-C.; Liu, C.-C.; Liang, X.-D.; Chen, J.; Zhou, J.; Baloch, A.S.; Kan, L.; Zhou, B.; et al. Rab5, Rab7, and Rab11 Are Required for Caveola-Dependent Endocytosis of Classical Swine Fever Virus in Porcine Alveolar Macrophages. J. Virol. 2018, 92, e00797-18. [CrossRef] [PubMed]

54. Hernaez, B.; Alonso, C. Dynamin- and Clathrin-Dependent Endocytosis in African Swine Fever Virus Entry. J. Virol. 2009, 84, 2100-2109. [CrossRef] [PubMed]

55. Shi, B.-J.; Liu, C.-C.; Zhou, J.; Wang, S.-Q.; Gao, Z.-C.; Zhang, X.-M.; Zhou, B.; Chen, P.-Y. Entry of Classical Swine Fever Virus into PK-15 Cells via a pH-, Dynamin-, and Cholesterol-Dependent, Clathrin-Mediated Endocytic Pathway That Requires Rab5 and Rab7. J. Virol. 2016, 90, 9194-9208. [CrossRef]

56. Liu, P.; Rudick, M.; Anderson, R.G.W. Multiple Functions of Caveolin-1. J. Biol. Chem. 2002, 277, 41295-41298. [CrossRef] 
57. Lin, H.-Y.; Yang, Y.-T.; Yu, S.-L.; Hsiao, K.-N.; Liu, C.-C.; Sia, C.; Chow, Y.-H. Caveolar Endocytosis Is Required for Human PSGL-1-Mediated Enterovirus 71 Infection. J. Virol. 2013, 87, 9064-9076. [CrossRef]

58. Frampton, A.R.; Stolz, D.B.; Uchida, H.; Goins, W.F.; Cohen, J.B.; Glorioso, J.C. Equine Herpesvirus 1 Enters Cells by Two Different Pathways, and Infection Requires the Activation of the Cellular Kinase ROCK1. J. Virol. 2007, 81, 10879-10889. [CrossRef]

59. Nabi, I.R.; Le, P.U. Caveolae/raft-dependent endocytosis. J. Cell Biol. 2003, 161, 673-677. [CrossRef]

60. Rust, M.J.; Lakadamyali, M.; Zhang, F.; Zhuang, X. Assembly of endocytic machinery around individual influenza viruses during viral entry. Nat. Struct. Mol. Biol. 2004, 11, 567-573. [CrossRef]

61. De Vries, E.; Tscherne, D.M.; Wienholts, M.J.; Cobos-Jiménez, V.; Scholte, F.E.M.; García-Sastre, A.; Rottier, P.J.M.; De Haan, C.A.M. Dissection of the Influenza A Virus Endocytic Routes Reveals Macropinocytosis as an Alternative Entry Pathway. PLoS Pathog. 2011, 7, e1001329. [CrossRef] [PubMed]

62. Wu, R.; Tang, X.; Sheng, X.; Zhan, W. Relationship between Expression of Cellular Receptor-27.8kDa and Lymphocystis Disease Virus (LCDV) Infection. PLoS ONE 2015, 10, e0127940. [CrossRef] [PubMed]

63. Gerold, G.; Moeller, R.; Pietschmann, T. Hepatitis C virus entry: Protein interactions and fusion determinants governing productive hepatocyte invasion. Cold Spring Harb. Perspect. Med. 2020, 10, a036830. [CrossRef] [PubMed]

64. Lin, Y.-W.; Lin, H.-Y.; Tsou, Y.-L.; Ebenezer, C.; Hsiao, K.-N.; Shao, H.-Y.; Liu, C.-C.; Si, C.; Chong, P.; Chow, Y.-H. Human SCARB2 mediated entry and endocytosis of EV71. PLoS ONE 2012, 7, e30507. [CrossRef]

65. Kornilova, E. Receptor-mediated endocytosis and cytoskeleton. Biochemistry 2014, 79, 865-878. [CrossRef]

66. Matsuda, M.; Suzuki, R.; Kataoka, C.; Watashi, K.; Aizaki, H.; Kato, N.; Matsuura, Y.; Suzuki, T.; Wakita, T. Alternative endocytosis pathway for productive entry of hepatitis C virus. J. Gen. Virol. 2014, 95, 2658-2667. [CrossRef]

67. Coyne, C.B.; Bergelson, J.M. Virus-Induced Abl and Fyn Kinase Signals Permit Coxsackievirus Entry through Epithelial Tight Junctions. Cell 2006, 124, 119-131. [CrossRef]

68. Torgersen, M.L.; Skretting, G.; Van Deurs, B.; Sandvig, K. Internalization of cholera toxin by different endocytic mechanisms. J. Cell Sci. 2001, 114, 3737-3747.

69. Wu, R.; Sheng, X.; Tang, X.; Xing, J.; Zhan, W. Transcriptome Analysis of Flounder (Paralichthys olivaceus) Gill in Response to Lymphocystis Disease Virus (LCDV) Infection: Novel Insights into Fish Defense Mechanisms. Int. J. Mol. Sci. 2018, 19, 160. [CrossRef]

70. Hayer, A.; Stoeber, M.; Ritz, D.; Engel, S.; Meyer, H.; Helenius, A. Caveolin-1 is ubiquitinated and targeted to intralumenal vesicles in endolysosomes for degradation. J. Cell Biol. 2010, 191, 615-629. [CrossRef]

71. Guo, M.; Chen, K.; Lv, Z.; Shao, Y.; Zhang, W.; Zhao, X.; Li, C. Bcl-2 mediates coelomocytes apoptosis by suppressing cytochrome $c$ release $T$ in Vibrio splendidus challenged Apostichopus japonicus. Dev. Comp. Immunol. 2020, 103, 103533. [CrossRef]

72. Zhao, Y.; Guo, M.; Lv, Z.; Zhang, W.; Shao, Y.; Zhao, X.; Li, C. Fas-associated death domain (FADD) in sea cucumber (Apostichopus japonicus): Molecular cloning, characterization and pro-apoptotic function analysis. Dev. Comp. Immunol. 2020, 108, 103673. [CrossRef] [PubMed]

73. Zhang, Y.; Wang, L.; Huang, X.; Wang, S.; Huang, Y.; Qin, Q. Fish Cholesterol 25-Hydroxylase Inhibits Virus Replication via Regulating Interferon Immune Response or Affecting Virus Entry. Front. Immunol. 2019, 10, 322. [CrossRef] [PubMed]

74. Sheng, X.; Wang, M.; Xing, J.; Zhan, W. Monoclonal antibodies against $27.8 \mathrm{kDa}$ protein receptor efficiently block lymphocystis disease virus infection in flounder Paralichthys olivaceus gill cells. Dis. Aquat. Org. 2012, 100, 19-27. [CrossRef] [PubMed]

(C) 2020 by the authors. Licensee MDPI, Basel, Switzerland. This article is an open access article distributed under the terms and conditions of the Creative Commons Attribution (CC BY) license (http://creativecommons.org/licenses/by/4.0/). 